\title{
Disentangling goods, labor, and credit market frictions in three European economies
}

\author{
Thomas Brzustowski \\ London School of Economics \\ Nicolas Petrosky-Nadeau \\ Federal Reserve Bank of San Francisco \\ Etienne Wasmer \\ Sciences Po, Paris and CEPR
}

December 2015

Working Paper 2015-22

http://www.frbsf.org/economic-research/publications/working-papers/wp2015-22.pdf

\section{Suggested citation:}

Brzustowski, Thomas, Nicolas Petrosky-Nadeau, Etienne Wasmer. 2015. “Disentangling goods, labor, and credit market frictions in three European economies.” Federal Reserve Bank of San Francisco Working Paper 2015-22. http://www.frbsf.org/economicresearch/publications/working-papers/wp2015-22.pdf

The views in this paper are solely the responsibility of the authors and should not be interpreted as reflecting the views of the Federal Reserve Bank of San Francisco or the Board of Governors of the Federal Reserve System. 


\title{
Disentangling goods, labor, and credit market frictions in three European economies*
}

\author{
Thomas Brzustowski, Nicolas Petrosky-Nadeau and Etienne Wasmer ${ }^{\dagger}$
}

December 18, 2015

\begin{abstract}
We build a flexible model with search frictions in three markets: credit, labor, and goods markets. We then apply this model (called CLG) to three different economies: a flexible, finance-driven economy (the UK), an economy with wage moderation (Germany), and an economy with structural rigidities (Spain). In the three countries, goods and credit market frictions play a dominant role in entry costs and account for $75 \%$ to $85 \%$ of total entry costs. In the goods market, adverse supply shocks are amplified through their propagation to the demand side, as they also imply income losses for consumers. This adds up to, at most, an additional $15 \%$ to $25 \%$ to the impact of the shocks. Finally, the speed of matching in the goods market and the credit market accounts for a small fraction of unemployment: Most of the variation in unemployment comes from the speed of matching in the labor market.
\end{abstract}

\footnotetext{
${ }^{*}$ This paper previously circulated under the title "A steady-state model of a non-Walrasian economy with three imperfect markets." We thank the participants of the conference in honor of Chris Pissarides, June-July 2015, the participants of seminars in Cologne (Macro group), U. Geneva, ILO seminar, and in particular Martin Scheffel, Matthieu Charpe, Frédéric Robert-Nicoud. These views are those of the authors and do not necessarily reflect the views of the Federal Reserve System. All remaining errors are our own. Etienne Wasmer also acknowledges support from ANR-11-LABX-0091 (LIEPP) and ANR-11-IDEX-0005-02.

${ }^{\dagger}$ In order London School of Economics; Federal Reserve Bank of San Francisco; and Sciences Po (Econ. Dept. and LIEPP)
} 


\section{Introduction}

This paper develops a model of credit, labor, and goods market frictions introduced in a symmetrical way, with matching functions associating, respectively, job seekers and vacancies, financial institutions and "projects," and "selling firms" and "customers." The model is kept tractable under a set of assumptions that can easily be removed to incorporate additional features. In particular, this article introduces a structure of search in the goods market and its relation to income that facilitates the exposition of the main concepts and, importantly, implies a convenient recursive structure of the model. As a result, solutions in each market are derived sequentially with equilibrium tightness in the goods market determined first. This leads to transparent and closed-form solutions characterizing a labor market equilibrium, extending the canonical search models. This also allows for a transparent calibration to several European economies, determining the role of entry costs in each of the three markets, the respective role of price and wage markups, and finally the role of complementarities between frictions in each market.

A classical search literature originally introduced economies with goods market frictions, where consumers needed to prospect in the goods market in order to consume (e.g., Diamond, 1971, 1982). Diamond (1982) assumed that two consumers were needed to consume indivisible units of goods (the coconuts). Diamond (1971) instead assumed two sides in the market, consumers and sellers. Only consumers searched for different shops. Shops were located in different places. The striking result of Diamond (1971) was that prices would converge to the monopsony price even with infinitely small search costs.

A recent and growing literature has revived these ideas. A similar logic where consumers and sellers are linked through a matching function in the goods market has been introduced in Wasmer (2009), Lehmann and Van der Linden (2010), Bai et al. (2011), Michaillat and Saez (2014) and Petrosky-Nadeau and Wasmer (2015). In this paper, we encompass these approaches and assume that firms have imperfect access to financial markets, then imperfect access to the labor market, and finally imperfect access to consumers. Consumers themselves face frictions to consume certain goods and must spend time and resources to access these search goods. As long as they are unsuccessful, they have excess income, which they spend on a non-frictional goodplaying the role of a numeraire. This convenient assumption of a numeraire absorbing the excess liquidity when agents do not access the search good is reminiscent of the night-and-day markets in the search and money literature (Lagos and Wright, 2005 and Nosal and Rocheteau (2011)). When the frictionless market opens in these models, any excess liquidity is absorbed so that agents start the next day being ex ante identical. This has been a decisive step to simplify quite substantially the rich money-search literature and develop its application in a large number of domains.

Although in this paper we focus on steady-state relations between markets, interesting cyclical properties have been studied in the goods market, and in particular in relation to the cyclical properties of intensive search margins (consumer search effort and shopping time, advertising efforts by firms). Procyclicality of goods market search effort has been established in Hall (2012) for advertising. Petrosky-Nadeau et al. (2015) provide an empirical test of the procyclicality of search effort by consumers. Their conclusions stand in contrast to Kaplan and Menzio (2013), who argue instead that consumer search effort is larger in recessions. The implications for fiscal policy in the face of procyclical disposable income, and the underlying question of fiscal multipliers, has been explored in Petrosky-Nadeau and Wasmer (2014). In Bethune et al. (2015), drops in demand from credit constrained consumers affect the labor market through a search frictional goods market in which firms' marginal revenue declines with the level of demand faced in the goods market. Thismechanism also appears in Petrosky-Nadeau and Wasmer (2015).

Section 2 first introduces search in the goods market and emphasizes the several important differences from classical economies, including labor search economies, that need to be clarified. 
The general equilibrium properties of the model are derived in the steady state in Section 3. Price and wage bargaining solutions are explored in Section 4. We quantify the role of each friction and the various complementarities between markets in three different European economies in Section 5. Section 6 concludes.

\section{A model with search in goods markets}

\subsection{Setup}

Time is continuous. Consumers have access to two types of goods: (i) one type of good is accessible with no frictions, indexed by 0 , can be thought of as a set of inferior goods (food, basic services, standard goods), and its price is normalized to unity; (ii) the other type of good, indexed by 1 , is subject to search frictions, and can either be interpreted as services or the flow consumption of a durable good such as cars, housing service, etc. This second good is produced by firms, while goods 0 will be produced by consumers, as discussed below. ${ }^{1}$

Hence, goods 0 are the goods regularly consumed without the need to search for them. Instead, goods 1 represent goods needing new search from time to time, due to both the arrival on the market of new consumption goods (e.g., a new restaurant in the neighborhood, a new brand of consumption good), or replacement of old goods previously consumed and hit by various shocks, specified below, such as changes in "consumer tastes" or the inability of firms to produce the good for a period of time.

\subsection{The life cycle of a new good}

A new search good can be produced through the following sequence. First, the firm develops a new project. The firm can be either an entirely new firm or an existing firm. In the latter case, this is the marginal project of that firm. This project has to be financed externally. Hence, in this early stage denoted by $c$, the firm attempts to form a first match with a financial intermediary. The intermediary and the "project" subsequently form a block that is called a "firm." However, this match can break down from time to time following exogenous events, dissolving the match in the financial market. Second, this newly formed block recruits a worker in a stage denoted by $v$ according to the standard labor matching process. Third, once the worker is recruited, the firm is able to produce and advertise to sell its good, and begins to search actively for a consumer. However, the firm does not generate profits yet. In the third phase of the life cycle of a firm, "search in the goods market" indicated by subscript $g$, the firm makes no revenue and incurs losses due to wage payments and operating costs. This stage precedes the final profit stage called stage $\pi$, in which it can sell to consumers and generate profits. Figure 1 summarizes the timing and notation of the various transitions between the different stages.

In the special case of the absence of search frictions in the goods market, stages $g$ and $\pi$ are confounded. In that limiting case, stage $g$ lasts an infinitely small amount of time. Instead, with a period of a positive length in stage $g$, the firm has to pay the wage to its worker, denoted by $w_{g}$. In stage $\pi$, after meeting with a consumer, the firm will obtain a price per period from the

\footnotetext{
${ }^{1} \mathrm{~A}$ convenient intuition to think of the differences between the two goods is to think of the two main sources of heterogeneity across goods: spatial (similar goods are sold in different places), and horizontal (some differentiation across products). Both types of heterogeneity lead to higher search frictions. Goods 0 are goods for which search is small, because they are sold in places known to the consumers and the degree of differentiation is low enough, or because the consumer has kept a record of their location and characteristics. Goods 1 are goods for which, either locations must be found or characteristics must be investigated. Once consumed, though, they are not subject to search frictions, until the consumption match dissolves.
} 


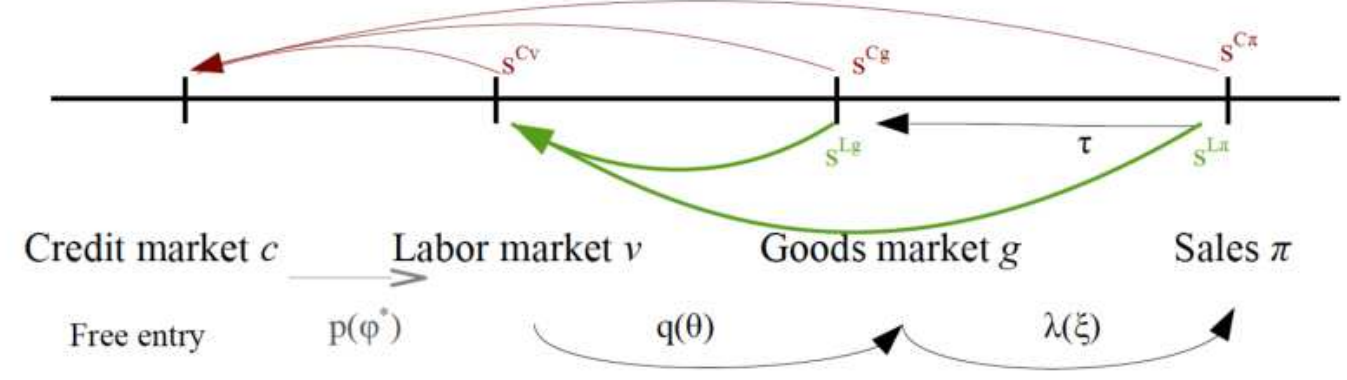

Figure 1: Timing and transition rates of a marginal project producing the search good: credit destruction $s^{C k}, k=c, g, \pi$, labor turnover $s^{L k}, k=g, \pi$ and taste shocks $\tau$; credit matching rate $p(\phi)$, labor hiring rate $q(\theta)$ and goods market matching rate $\lambda(\xi)$.

consumer $\mathcal{P}$ who will purchase the flow of service of the goods, as a long-term relationship. This assumption characterizes the existence of specificity in the match formed in the goods market. The firm pays a wage $w_{\pi}$.

\subsection{Random matching in labor and credit}

As in Wasmer and Weil (2004), denote by $p$ the rate at which the project meets the creditor, and by $\check{p}$ the rate at which the creditor meets - and implicitly both screens and accepts the project. There is an identity in the financial market between the total number of matches, $\mathcal{M}_{C}$, the number of matched projects and the number of matched creditors in a unit of time: $\mathcal{M}_{C}=p \mathcal{N}_{c}=\check{p} \mathcal{B}_{c}$. The ratio of project to creditors searching in the credit market, $\phi=\mathcal{N}_{c} / \mathcal{B}_{c}$, is a measure of conditions in the financial market called financial market tightness, and $\check{p}=\phi p$. Matching is governed by a constant returns to scale function with the mass of investment projects and creditors searching in the financial market as arguments:

$$
\mathcal{M}_{C}\left(\mathcal{N}_{c}, \mathcal{B}_{c}\right) \quad \text { with } \quad \partial \log \mathcal{M}_{C} / \partial \log \mathcal{B}_{c}=\eta_{C}(\phi)
$$

where $\eta_{C}(\phi)$ is the elasticity of matching in the financial market with respect to searching investment projects. The transition rates for investment projects and creditors are functions of credit market tightness with $p^{\prime}(\phi)<0$ and $\check{p}^{\prime}(\phi)>0$.

Similarly, following the macro-labor literature and Pissarides (2000), we assume the existence of a constant returns to scale matching function in the labor market:

$$
\mathcal{M}_{L}=\mathcal{M}_{L}(\mathcal{V}, \mathcal{U}) \text { with } \partial \log \mathcal{M}_{L} / \partial \log \mathcal{U}=\eta_{L}(\theta)
$$

where $\theta=\mathcal{V} / \mathcal{U}$ is a measure of labor market tightness and $\eta_{L}(\theta)$ is the elasticity of matching with respect to unemployment. We denote by $f(\theta)$ the per-unit of time rate at which unemployed workers find a job equal to $\mathcal{M}_{L} / \mathcal{U}$, and $q(\theta)=\mathcal{M}_{L} / \mathcal{V}$ the corresponding hiring rate on the firm's perspective. We have $f(\theta) \equiv \theta \cdot q(\theta)$ and $q^{\prime}(\theta) \leq 0$.

\subsection{Goods market}

We denote, respectively, by $\mathcal{D}_{M}$ and $\mathcal{D}_{U}$ the number of consumers matched with goods 1 or unmatched. We also denote by $\mathcal{N}_{\pi}$ and $\mathcal{N}_{g}$ the number of selling and searching firms (for consumers), 
respectively. The total number of employed workers is therefore equal to the total number of firms in each stage, that is:

$$
1-\mathcal{U}=\mathcal{N}_{\pi}+\mathcal{N}_{g}
$$

We also assume that each firm can serve only one consumer. This further implies:

$$
\mathcal{D}_{M} \equiv \mathcal{N}_{\pi}
$$

This is therefore a one-firm/one-worker/one-consumer model.

As in the standard search and matching models, we introduce the tightness of the goods market as:

$$
\xi=\frac{\mathcal{D}_{U}}{\mathcal{N}_{g}} .
$$

It follows that the transition rates for firms and for consumers are given, respectively, by:

$$
\begin{aligned}
& \frac{\mathcal{M}_{G}\left(\mathcal{D}_{U}, \mathcal{N}_{g}\right)}{\mathcal{N}_{g}}=\lambda(\xi) \quad \text { with } d \lambda / d \xi>0 \\
& \frac{\mathcal{M}_{G}\left(\mathcal{D}_{U}, \mathcal{N}_{g}\right)}{\mathcal{D}_{U}}=\lambda(\xi) / \xi=\check{\lambda}(\xi) \quad \text { with } d \check{\lambda} / d \xi<0 .
\end{aligned}
$$

The total number of prospective consumers, that is the consumers willing to exert search effort on the goods market to be able to consume search good 1, has to be determined. We assume that only employed workers, who have access to a full salary can consume search good 1 . That is, we are assuming that all income available to the unemployed is spent on essential goods. The unemployed have no additional disposable income to spend on the search good. In this simplified economy with two goods, one (goods 0 ) is the essential good while the other one (goods 1 ) is a normal good and, in the current case, even a luxury good not accessible to the unemployed. It follows that the sum of unmatched and matched consumers of goods 1 sums up to total employment:

$$
\mathcal{D}_{U}+\mathcal{D}_{M}=1-\mathcal{U}
$$

\subsection{Match destruction}

Labor relations in stage $g$ and $\pi$ dissolve at an exogenous Poisson rate $s^{L k}$, with $k=g, \pi$. Credit relations in stage $v, g$ and $\pi$ dissolve at an exogenous Poisson rate $s^{C k}$, with $k=c, g, \pi$. Although in the calibration exercise these differences in separation rates across stages will not be very important, distinguishing them will have the virtue of following carefully the role of each parameter in the single free-entry equation condensing all the margins of the model exposed in next Section. In addition, we denote by $s^{L g, \pi}$ and $s^{C g, \pi}$ the average of these shocks across stages $g$ and $\pi$ : $s^{L g, \pi}=\left(\mathcal{N}_{g} s^{L g}+\mathcal{N}_{\pi} s^{L \pi}\right) /\left(\mathcal{N}_{g}+\mathcal{N}_{\pi}\right)$ and $s^{C g, \pi}=\left(\mathcal{N}_{g} s^{C g}+\mathcal{N}_{\pi} s^{C \pi}\right) /\left(\mathcal{N}_{g}+\mathcal{N}_{\pi}\right)$.

Consumer relations also dissolve, for two main reasons. First, the consumer of goods 1 may change tastes, leading to a separation in the consumer-seller relationship. Such a separation event arrives with Poisson intensity $\tau$. Second, consumers, who are also workers, may face an income shock due to job separation from turnover in either the labor or credit market terminating their

employment. The loss of purchasing power arrives on average at rate $s^{L g, \pi}+s^{C g, \pi}$ depending on whether the consumer is in a firm at stage $g$ or $\pi$. This is unobserved by the selling firm. It follows that the rate of consumption-match termination $s^{G}$ is the sum of the pure taste shock the consumer income shocks. We use the compact notation $s^{G}=\tau+s^{L g, \pi}+s^{C g, \pi}$. 


\subsection{Additional notations and concepts}

\section{Unused production capacities}

There are unused resources at the firm level. Firms have the ability to produce, but not necessarily to sell unless they find a consumer. Production takes place only when the match with the consumer has been formed. Therefore, the firm does not use its capacity to produce in the stage where it has no consumer. The search frictions in the goods market introduce a new concept, the rate of capacity utilization. This can be defined as:

$$
\mu_{G}=\frac{\mathcal{N}_{\pi}}{\mathcal{N}_{\pi}+\mathcal{N}_{g}}
$$

The rate of capacity utilization is the ratio of firms matched with a consumer, $\mathcal{N}_{\pi}$, to the total number of firms matched with a worker who could, potentially, produce, $\mathcal{N}_{\pi}+\mathcal{N}_{g}=\mathcal{N}$. This rate is a widely available statistic and will be used subsequently for calibrating the frictional economy.

\section{Transfers, Lucas trees, and the circular flows of income in the economy}

The firm receives a unit price $\mathcal{P}$ from consumers in exchange for $x$ units of goods 1 produced. The good produced is assumed to be indivisible: it must be fully consumed by the consumer. Here, $x$ must therefore be interpreted as quality of the good, entering the utility function of the consumer. The consumer must, in addition, have the resources at the time of the meeting with the firm to pay for the price $\mathcal{P}$. No credit is allowed to customers, unlike Bethune et al. (2015) and Branch et al. (2015) in which there is consumer credit.

At each point in time there is a mass $\mu_{G}(1-\mathcal{U})=\mu_{G} \mathcal{N}$ of firms in stage $\pi$ that is both producing and selling goods 1 . In the aggregate, firms generate gross revenues $\mu_{G} \mathcal{N} \mathcal{P} x$, and have total wage and search costs $\left[\mu_{G} w_{\pi}+\left(1-\mu_{G}\right) w_{g}\right] \mathcal{N}+\gamma \mathcal{V}$. A fraction $\mu_{G}$ of firms, those in a goods market match, pay the wage $w_{\pi}$, while the other firms pay the wage $w_{g}$. The difference between gross revenue and costs, the net revenues generated by firms in this economy, is rebated to unemployed workers as well as employed workers in equal shares. Denote by $\mathcal{K}_{U}$ and $\mathcal{K}_{W}$ the dividends received by, respectively, the unemployed and employed, in the aggregate.

Importantly, workers receive additional resources expressed in terms of the numeraire good 0 , that are the fruits (in numeraire) of a Lucas tree growing in their individual garden. Each agent is endowed in each unit of time a quantity $\bar{y}^{0}$ of additional resources. Hence, total disposable income of employed workers is now:

$$
\left(\mu_{G} \mathcal{P} x+\bar{y}^{0}\right) \mathcal{N}-\gamma \mathcal{V}-\mathcal{K}_{U} \lessgtr \mu_{G} \mathcal{N} \mathcal{P} x
$$

In the absence of the Lucas tree $\left(\bar{y}^{0}=0\right)$, and given the discussion above, consumers' aggregate net income is below the value of sales of goods $1 \mathcal{N}_{\pi} \mathcal{P} x .^{2}$

\footnotetext{
${ }^{2}$ Under low values of $\bar{y}^{0}$, consumers would be unable to purchase the search good. A non degenerate equilibrium thus requires a positive and large enough value of $\bar{y}^{0}$ so that a non trivial equilibrium exists. As evident from equation (7), this endowment must be greater than the sum of labor search costs and the share of dividends accruing to the unemployed, $\gamma \mathcal{V}+\mathcal{K}_{U}$.
} 


\section{Utility, individual and aggregate consumption}

The utility function of consumers depends on the consumption of both goods 1 and 0 , and of leisure denoted by $l$. It is denoted by $v\left(c^{1}, c^{0}, l\right)$ where the first input is consumption of the search good, the second of the numeraire, and the third leisure. We denote by $c_{U}^{0}$ and $c_{M}^{0}$ the consumption of the numeraire by, respectively, the employed unmatched with a search good and employed matched with a search good. We normalize leisure so that employed workers consume no leisure and unemployed workers may consume up to a fixed quantity of leisure denoted by $z$. Unmatched consumers are employed and therefore have no leisure, and a flow utility $v\left(0, c_{U}^{0}, 0\right)$. Matched consumers have a flow utility $v\left(x, c_{M}^{0}, 0\right)$.

The viability of the search economy requires that consumers prefer the frictional good to the numeraire, otherwise they would not search for good 1. The equilibrium must therefore be such that:

$$
v\left(x, c_{M}^{0}\right)>v\left(0, c_{U}^{0}\right)
$$

The unemployed can freely transform part or all their leisure endowment $z$ into additional production of the numeraire, which insures an equilibrium between demand and supply of the numeraire. Since the exact quantity of leisure transformed is irrelevant to the market equilibrium, we only report these calculations in Appendix A.

\section{Steady-state free-entry equilibrium}

\subsection{Bellman equations and free-entry}

We are now able to introduce the main Bellman equations of the recursive structure of the model. Upon the realization of any of the two separation shocks $s^{L k}, k=g, \pi$, the firm returns to the vacancy stage $J_{v}$ in the entry equilibrium. Similarly, under the realization of one of the three separation shocks $s^{C k}, k=v, g, \pi$, the firm returns to the credit stage. Figure 1 summarizes the timing of the various transitions.

Let $E_{c}, E_{v}, E_{g}$, and $E_{\pi}$ be the respective steady-state asset values of an entrepreneur in each period (credit stage, labor stage, goods stage, profit). Let $B_{c}, B_{v}, B_{g}$, and $B_{\pi}$ be the respective steady-state asset values of a bank in each period (credit stage, labor stage, goods stage, profit). The corresponding equations are in Appendix B. Under the assumption of free-entry, that is, each marginal project can enter the credit-stage freely, one has $B_{c}=0$ and $E_{c}=0$. Denote by $J_{v}, J_{g}$ and $J_{\pi}$ the firm value, that is of $E_{k}+B_{k}, k=v, g, \pi$ the block formed by the "project" in different stages and the financial intermediary. We impose a free-entry condition in the credit market: $E_{c}=0, B_{c}=0$ as in Wasmer and Weil (2004).

We define $K(\phi)$ as a measure of the total expected cost of financial intermediation, as the sum of expected cost of firms searching for a bank and of the expected cost of the bank searching for a suitable project to finance, that is,

$$
K(\phi)=\frac{\kappa_{B}}{\phi p(\phi)}+\frac{\kappa_{I}}{p(\phi)} .
$$

Under free-entry, one has:

$$
\begin{aligned}
\left(r+s^{C v}\right) J_{v}= & \left(r+s^{C v}\right) K=-\gamma+q(\theta)\left(J_{g}-J_{v}\right) \\
& \left(r+s^{C g}\right) J_{g}=-w_{g}+s^{L g}\left(J_{v}-J_{g}\right)+\lambda\left(J_{\pi}-J_{g}\right) \\
& \left(r+s^{C \pi}\right) J_{\pi}=x \mathcal{P}-w_{\pi}+s^{L \pi}\left(J_{v}-J_{\pi}\right)+s^{G}\left(J_{g}-J_{\pi}\right) .
\end{aligned}
$$


All the model can therefore be collapsed into a single equation linking entry costs and future expected profits, in combining the recursive equations above and eliminating the value functions. We have (see Appendix B for a proof):

$$
\begin{aligned}
& \left.\left(1+\frac{r+s^{C v}}{q}\right) K+\frac{\gamma}{q(\theta)}+\frac{1}{1-Q_{\pi} Q_{g}}\left(\frac{w_{g}-s^{L g} K}{r+s^{L g}+s^{C g}+\lambda}\right)=\frac{Q_{g}}{1-Q_{\pi} Q_{g}}\left(\frac{x \mathcal{P}-w_{\pi}+s^{L \pi} K}{r+s^{L \pi}+s^{C \pi}+s^{G}}\right) 11\right) \\
& \text { Entry Costs in Credit, Labor and Goods Markets Present Discounted Value of profits } \\
& \text { with } \\
& Q_{g}=\frac{\lambda}{r+s^{L g}+s^{C g}+\lambda} ; \quad Q_{\pi}=\frac{s^{G}}{r+s^{L \pi}+s^{C \pi}+s^{G}} .
\end{aligned}
$$

The left-hand side is the sum of three terms, expressed in future value of the vacancy stage. The first term is the future value of financial costs, the second term is the value of hiring costs, the third term is the value of wages net of the recovery costs $K$ after labor turnover in stage $g$. The right-hand side is the expected discounted value of profits and recovery cost after labor turnover in stage $\pi$. We will extensively study this equation and in particular calculate its different components in the quantitative exercise. The expression has various limiting cases capturing the intuition of the decomposition above.

\section{CL model with perfect goods market: $\lambda \rightarrow+\infty, Q_{g} \rightarrow 1$}

In this limit case, one obtains that the entry costs due to financial markets and the hiring costs in the labor market add up and must be equal to the present-discounted value of profits:

$$
\left(1+\frac{r+s^{C v}}{q}\right) K+\frac{\gamma}{q}=\frac{x \mathcal{P}-w_{\pi}+s^{L \pi} K}{r+s^{L \pi}+s^{C \pi}} .
$$

\section{LG model with perfect credit markets: $K \rightarrow 0$}

In this limit case, one obtains that entry costs are the sum of hiring costs and deficits of the firm when it does not sell, and they are equal to the properly discounted sum of profits in stage $\pi$. Note that credit shocks $s^{C}$ (whereby the firm is back to the entry stage $E_{c}=0$ ) could further be eliminated, but the absence of credit market imperfection does not imply the absence of such destructive shocks:

$$
\frac{\gamma}{q}+\frac{1}{1-Q_{\pi} Q_{g}}\left(\frac{w_{g}}{r+s^{L g}+s^{C g}+\lambda}\right)=\frac{Q_{g}}{1-Q_{\pi} Q_{g}}\left(\frac{x \mathcal{P}-w_{\pi}}{r+s^{L \pi}+s^{C \pi}+s^{G}}\right) .
$$

\section{L model with both perfect credit and goods market: $K \rightarrow 0$ and $\lambda \rightarrow+\infty, Q_{g} \rightarrow 1$}

In this limit, one reverts to the standard Pissarides equation where entry costs are equal to future discounted profits:

$$
\frac{\gamma}{q}=\frac{x \mathcal{P}-w_{\pi}}{r+s^{L \pi}+s^{C \pi}} .
$$




\subsection{Steady-state solutions for goods and credit market tightness}

Going back to the general case of frictions in three markets, the model is solved recursively. The first step is to derive equilibrium goods market tightness. This is easy from the steadystate equations governing the evolution of the various stocks of: (i) employment in goods market matched firms; (ii) employment in unmatched firms in the goods market; (iii) unemployment; (iv) vacancies; (v) matched consumers; and (vi) unmatched consumers. The equations for the stocks are (see Appendix C for more details):

$$
\begin{aligned}
\mathcal{N}_{\pi}+\mathcal{N}_{g} & =\left[1+\lambda /\left(s^{L g, \pi}+s^{G}\right)\right] \mathcal{N}_{g} \\
\mathcal{D}_{M}+\mathcal{D}_{U} & =\left[1+\check{\lambda} /\left(s^{L g, \pi}+s^{G}\right)\right] \mathcal{D}_{U} \\
\left(\lambda+s^{L g, \pi}\right) \mathcal{N}_{g} & =\mathcal{N}_{\pi} s^{G}+\mathcal{M}_{L}(\mathcal{U}, \mathcal{V}) \\
\mathcal{M}_{L}(\mathcal{U}, \mathcal{V}) & =s^{L g, \pi}(1-\mathcal{U}) \\
\mathcal{N}_{g}+\mathcal{N}_{\pi} & =1-\mathcal{U} \\
\mathcal{D}_{U}+\mathcal{D}_{M} & =1-\mathcal{U} .
\end{aligned}
$$

One can therefore solve the six stock variables with the six equations above. Goods market tightness is the ratio of firms willing to sell to prospective consumers. Using the ratio of equations (15) and (16) on the one hand, and along with the fact that $\mathcal{N}_{g}+\mathcal{N}_{\pi}=\mathcal{D}_{U}+\mathcal{D}_{M}$ from equations (19) and (20), we have that:

$$
\frac{\mathcal{N}_{g}+\mathcal{N}_{\pi}}{\mathcal{D}_{M}+\mathcal{D}_{U}}=\frac{1+\lambda /\left(s^{L g, \pi}+s^{G}\right)}{1+\check{\lambda} /\left(s^{L g, \pi}+s^{G}\right)} \frac{\mathcal{N}_{g}}{\mathcal{D}_{U}}=1
$$

Property 1 (steady-state goods market tightness). Consumption tightness $\xi$ in a steady state is equal to 1 if only the employed workers have access to the frictional good:

$$
\mathcal{D}_{U}+\mathcal{D}_{M}=\mathcal{N} \quad \Rightarrow \quad \xi^{*}=1
$$

The proof amounts to solving a fixed point problem:

$$
\xi=\frac{1+\lambda(\xi) /\left(s^{L g, \pi}+s^{G}\right)}{1+\check{\lambda}(\xi) /\left(s^{L g, \pi}+s^{G}\right)} .
$$

Using $\check{\lambda}(\xi)=\lambda(\xi) / \xi$, it is easy to see that $\xi=1$ is one such fixed point. It can be shown that, under an Inada condition on the matching function, there is a second fixed point $\xi=0$ corresponding to a degenerate case with no market. This would be a subsistence economy where everyone consumes the numeraire in quantity $\bar{y}^{0}$. There is no other fixed point for a standard matching function. When $\xi>0$, one has $\xi+\lambda(\xi) /\left(s^{L g, \pi}+s^{G}\right)=1+\lambda(\xi) /\left(s^{L g, \pi}+s^{G}\right)$, which leads immediately to $\xi=1 .^{3}$ This property determines not only goods market tightness, but also the value of transition rates in the goods market. Hence, from now on, we have $\check{\lambda}(1)=\lambda(1)=\lambda$.

\footnotetext{
${ }^{3}$ This result, when the ratio $\left(\mathcal{N}_{g}+\mathcal{N}_{\pi}\right) /\left(\mathcal{D}_{M}+\mathcal{D}_{U}\right)$ is equal to 1 , arises from the apparently innocuous assumption that only the employed workers search for the search good. It can be interpreted as a stochastic version of the old Say's law that demand equals supply. The firm produces one good, each consumer consumes one good,
} 
In regards to the repayment $\psi$ from the firm to the creditor in stage $\pi$, it is the solution to the following conventional Nash bargaining game:

$$
\psi=\operatorname{argmax}\left(B_{v}-B_{c}\right)^{\alpha_{C}}\left(E_{v}-E_{c}\right)^{1-\alpha_{C}}
$$

where $\alpha_{C} \in(0,1)$ is the relative bargaining strength of the creditor. The solution to this problem depends on the assumed effect of the repayment $\psi$ on the wage to labor $w$. Under the assumption that, from the perspective of bargaining in the financial market, the future wage $w$ paid to the worker does not depend on the repayment $\psi$, the slopes of the value of the profit stage for both the creditor and the project are equal in absolute value. That is, $\partial B_{\pi} / \partial \psi=-\partial E_{\pi} / \partial \psi=1 /\left(r+s^{T}\right)$ where $s^{T}=s^{G}+s^{L \pi}+s^{C \pi}$.

It then follows that the absolute value of slopes for the asset values of the labor search stage are also equal: $\partial B_{v} / \partial \psi=-\partial E_{v} / \partial \psi=Q_{L} \times 1 /\left(r+s^{T}\right)$. The Nash sharing rule for $\Psi$ can thus be written as:

$$
\left(1-\alpha_{C}\right)\left(B_{v}-B_{c}\right)=\alpha_{C}\left(E_{v}-E_{c}\right)
$$

The sharing rules can be rearranged as: $B_{v}=\alpha_{C} J_{v}$ and $E_{v}=\left(1-\alpha_{C}\right) J_{v}$, which states that the creditor receives a share $\alpha_{C}$ of the match surplus $J_{v}$, while a share $\left(1-\alpha_{C}\right)$ accrues to the project. Recall that free entry in the financial market leads to values of the labor search stage $B_{v}=\kappa_{B} /(\phi p(\phi))$ and $E_{v}=\kappa_{I} / p(\phi)$.

Property 2 (steady-state credit market tightness). Combining the above equations with the equation for Nash bargaining over the repayment (24) one reaches a unique solution for financial market tightness, $\phi^{*}$ and repayment $\psi$ :

$$
\begin{aligned}
\phi^{*} & =\frac{\kappa_{B}}{\kappa_{I}} \frac{1-\alpha_{C}}{\alpha_{C}} \\
\frac{\psi}{r+s^{T}} & =\alpha_{C} \frac{x \mathcal{P}-w_{\pi}}{r+s^{T}}+\left(1-\alpha_{C}\right)\left(\frac{1-Q_{g} Q_{\pi}}{Q_{g}} \cdot \frac{\gamma}{q(\theta)}+\frac{w_{g}}{\lambda}\right)
\end{aligned}
$$

Equilibrium financial market tightness, represented in equation (25), is increasing in the ratio of search costs for creditor $\kappa_{B}$ to the flow search costs for investment project $\kappa_{I}$. An increase in $\kappa_{B}$ leads to fewer creditors searching in the market and hence a longer duration of search for projects. In contrast, if the creditor receives a larger share of the credit match surplus, and thus a larger share of the value of a job opening and the profit flows during production, the free entry equilibrium will have a lower tightness of the financial market. This second property was proved in Wasmer and Weil (2004). The present discounted value of the repayment to the creditor during the profit stage, $\psi /\left(r+s^{T}\right)$, is an $\alpha_{C}$ weighted average of future profits of streams to the creditorproject match, $\left(x \mathcal{P}-w_{\pi}\right) /\left(r+s^{T}\right)$, and their past search costs in the labor and goods market. Under perfect goods market, $\lambda \rightarrow \infty$ and $Q_{g}=1 ; Q_{\pi}=0$. In this case, the second term converges to $\gamma / q(\theta)$.

The model is now partially solved since the first two blocks, financial and goods market tightnesses are fully determined. Price and wages now remain to be solved for, which is done next.

and each firm employs one employee-consumer. If instead each firm employed, say, two workers, this would lead to the creation of two consumers and thus goods market tightness would be equal to 2 , in the steady state. If conversely, each firm produced two units of goods, each worker-consumer would be able to consume two units of goods (in another firm) and therefore goods market tightness would be equal to half unity. Adapting this logic, if each firm could produce $n_{q}$ units and employed $n_{w}$ workers, the steady-state goods market tightness would be equal to $n_{w} / n_{q}$. Nonetheless, goods market tightness would still be a constant of parameters. 


\section{Bargaining relations in labor and goods market}

Before solving for wages, one can first simplify the structure of the model. Having different turnover rates by stage of the firm led to transparent interpretations of the various parameters in the entry equation (11). From now on, we can however simplify the turnover structure of the model and assume $s^{L g}=s^{L \pi}=s^{L}$ and $s^{C v}=s^{C g}=s^{C \pi}=s^{C}$; we thus have:

$$
\begin{aligned}
& r J_{v}=-\gamma+q\left(J_{g}-J_{v}\right)+s^{C}\left(J_{c}-J_{v}\right) \\
& r J_{g}=-w_{g}+\lambda\left(J_{\pi}-J_{g}\right)+s^{C}\left(J_{c}-J_{g}\right)+s^{L}\left(J_{v}-J_{g}\right) \\
& r J_{\pi}=x \mathcal{P}-w_{\pi}+s^{C}\left(J_{c}-J_{\pi}\right)+s^{G}\left(J_{g}-J_{\pi}\right)+s^{L}\left(J_{v}-J_{\pi}\right) .
\end{aligned}
$$

At each step, the existence of search frictions creates rents and those rents are conveniently split by Nash-bargaining. Nash-bargaining is commonly applied in the literature and this allows for easier comparability. We first start with a simple sequence of events where labor and goods lead to bilateral negotiations in each market, with shares of the firm/project being respectively $1-\alpha_{L} ; 1-\alpha_{G}$, that is, shares of the worker and consumer $\alpha_{L} ; \alpha_{G}$. To simplify the exposition, we will first start with a perfect credit market and generalize the model just after. That is, subsections 4.1 and 4.2 present first the solution with no credit frictions $(K=0)$ and then extend it easily to the case $K>0$. The Appendix also derives the full case with $K>0$ and different turnover rates across stages of the firm.

\subsection{Price determination under perfect financial markets}

Consumer-producer relationships are costly to create as they require several steps with direct costs (search) and have related opportunity costs. It is therefore natural to adopt a price determination rule that is the outcome of bargaining between the firm and the consumer. In what follows, on price and wage determination, we assume that bargaining takes places at the time of the meeting.

In addition, we make the simplifying assumption that workers are paid the same wage $w$ whether or not their employer is matched with a consumption. This implies that $w_{g}=w_{\pi}=w$, an assumption which greatly simplifies the analysis without being central to the main results. Rigidities, in the spirit of Gertler and Trigari (2009) can justify this assumption. Alternatively, this equality of wages would arise in the presence of collective bargaining between workers and firms. Additional alternative assumptions are discussed in the concluding Section, and they do not qualitatively alter the main results. Different wages and alternative timing are fully explored in the Appendix.

A newly employed worker is by definition a consumer not yet matched with a product in the goods market. Its present discounted utility is denoted by $W_{n 0}$. After a period of random search, (s)he reaches the consumption stage 1 in which (s)he consumes the frictional good. The present discounted utility in this stage is denoted by $W_{n 1}$. At any time, the consumer may be hit by a labor turnover shock, would move to unemployment and would have a present discounted utility $W_{u}$. This arises with probability per unit of time $s^{L}$. Finally, a matched consumer may exit the consumption match but remain employed if a goods match termination shock occurs. These arrive at rate $s^{G}$, which includes both the taste shock $\tau$, and the possible disruption of production due to the risk of labor turnover $s^{L}$. In both cases the consumer returns to the goods market search stage with asset value, $W_{n 0}$.

The Bellman equations of consumers, using the earlier result that $\check{\lambda}(1)=\lambda(1)=\lambda$ in a 
stationary equilibrium, are:

$$
\begin{aligned}
r W_{n 0} & =v\left(0, \bar{y}^{0}+w, 0\right)+\lambda\left(W_{n 1}-W_{n 0}\right)+s^{L}\left(W_{u}-W_{n 0}\right) \\
r W_{n 1} & =v\left(x, \bar{y}^{0}+w-\mathcal{P} x, 0\right)+s^{L}\left(W_{u}-W_{n 1}\right)+s^{G}\left(W_{n 0}-W_{n 1}\right) \\
r W_{u} & =v\left(0, \bar{y}^{0}, z\right)+f(\theta)\left(W_{n 0}-W_{u}\right)
\end{aligned}
$$

where the last equation is based on the fact that the unemployed have an additional $z$ units of leisure. The surplus of the consumer, $W_{n 1}-W_{n 0}$, is the difference in its valuation of the consumption stage and the search stage. Subtracting (30) from (31) we have the consumer's surplus as $W_{n 1}-W_{n 0}=\frac{v\left(x, \bar{y}^{0}+w-\mathcal{P} x\right)-v\left(0, \bar{y}^{0}+w\right)}{r+s^{L}+s^{G}+\lambda}$. The main results are clear under a linear utility setup. While richer dynamics require some concavity in utility $v$ with respect to goods 0 , the exposition of the main concepts of the LG model can accommodate a linear utility. Assume that $v\left(x, c^{0}\right)=\Phi x+c^{0}+l$, where the marginal utility of goods 0 is 1 (hence it is a numeraire), and the marginal utility of goods 1 is $\Phi>1$. A non degenerate equilibrium will therefore require $\Phi>\mathcal{P}$. Under these preferences we obtain a simpler expression for the the consumer's surplus :

$$
W_{n 1}-W_{n 0}=\frac{\Phi x-\mathcal{P} x}{r+s^{L}+s^{G}+\lambda} .
$$

The production of goods 0 has disappeared from the consumption surplus due to the assumption of linearity. The surplus from a goods market match is the discounted present value of flow net utility from consumption of the search good $(\Phi-\mathcal{P}) x$. In a Walrasian market, for comparison, the price is the marginal utility of consumption of the good, and the consumer surplus is driven to zero at the equilibrium price.

In this search frictional goods market, prices are bargained and set according to a Nash-sharing rule. The price is the solution to

$$
\mathcal{P}=\operatorname{argmax}\left(W_{n 1}-W_{n 0}\right)^{\alpha_{G}}\left(J_{\pi}-J_{g}\right)^{1-\alpha_{G}}
$$

where $\alpha_{G} \in(0,1)$ is the consumer's bargaining weight. The price must therefore satisfy the share rule $W_{n 1}-W_{n 0}=\frac{\alpha_{G}}{1-\alpha_{G}}\left(J_{\pi}-J_{g}\right)$. The firm's surplus with respect to the consumer relation is, subtracting (28) from (29): $J_{\pi}-J_{g}=\frac{\mathcal{P} x-w_{\pi}+w_{g}}{r+s^{L}+s^{G}+\lambda}$.

If we make the earlier simplifying assumption that $w_{g}=w_{\pi}$, the wage cancels out of the surplus of the firm. Combining the definitions on the consumer and firms goods market surplus with the Nash share rule leads to the bargained price:

$$
\mathcal{P} x=\left(1-\alpha_{G}\right) \Phi x .
$$

The price depends on the marginal utility for the good, $\Phi$, and the relative bargaining power of the seller $\left(1-\alpha_{G}\right)$. The property that the price is a function of consumer preferences and bargaining parameters is a general one. It also arises when the wage is allowed to vary across stages $g$ and $\pi$.

\subsection{Wage determination under perfect financial markets}

We make the assumption of an identical wage $w$ at idle firms (stage g) and selling firms (stage $\pi)$. The wage is negotiated when the firm is in the goods market stage $g$. As we saw in the previous section, this assumption on wage implies that the wage does not affect the capital gain from a match in the goods market for either the consumer or the firm. The wage drops out of the expression of a match surplus for both the consumer and the firm.

The bargained wage is the outcome of

$$
w=\operatorname{argmax}\left(J_{g}-J_{v}\right)^{1-\alpha_{L}}\left(W_{n 0}-W_{u}\right)^{\alpha_{L}}
$$


leading to the labor match surplus sharing rule: $\left(1-\alpha_{L}\right)\left(W_{n 0}-W_{u}\right)=\alpha_{L}\left(J_{g}-J_{v}\right)$. Using the definition of the asset values, the wage can be expressed as a function of the firm's surplus with respect to the consumer:

$$
w=\left(1-\alpha_{L}\right)\left(r W_{u}-\bar{y}^{0}\right)+\left(\frac{\alpha_{L}-\alpha_{G}}{1-\alpha_{G}}\right) \lambda\left(J_{\pi}-J_{g}\right)
$$

and then using the expression for the seller's surplus in the previous subsection and the discounting term $Q_{g}^{\prime}=\lambda /\left(r+s^{L}+s^{G}+\lambda\right)$, the wage in the labor market can be linked to the price in the goods market:

$$
w=\left(1-\alpha_{L}\right) z+\alpha_{L} \gamma \theta+\left(\frac{\alpha_{L}-\alpha_{G}}{1-\alpha_{G}}\right) Q_{g}^{\prime} \mathcal{P}_{x} .
$$

Again, simpler cases lead to the main intuitions. The Pissarides case is obtained when $Q_{g}^{\prime}=1$ (frictions in the goods market disappear) and when the firm does not lose any surplus to consumers $\left(\alpha_{G}=0\right): w=\left(1-\alpha_{L}\right) z+\alpha_{L}(\gamma \theta+\mathcal{P} x)$.

In the general case, replacing $\mathcal{P} x$ by its equilibrium value, the wage equation simplifies further to:

$$
w=\left(1-\alpha_{L}\right) z+\alpha_{L} \gamma \theta+\left(\alpha_{L}-\alpha_{G}\right) Q_{g}^{\prime} \Phi x .
$$

The term $\left(\alpha_{L}-\alpha_{G}\right) Q_{g}^{\prime} \Phi x$ can more easily be understood by rewriting it as $-\left(1-\alpha_{L}\right) Q_{g}^{\prime} \Phi x+$ $\left(1-\alpha_{G}\right) Q_{g}^{\prime} \Phi x$. The first, negative term, is a worker threat point effect: by having higher marginal utility $\Phi x$ from consuming the search good, the worker has more to lose from a breakdown in negotiations as the unemployed lose access to the search good. The second one is a consumer surplus effect: the firm obtains a fraction $\left(1-\alpha_{G}\right)$ of the marginal utility of the search good, and this leads to a higher wage. Simplifying, one obtains an impact of $\Phi x$ that is linear in $\alpha_{L}-\alpha_{G}$. Note however that the value of $\alpha_{L}-\alpha_{G}$ is always positive: if the bargaining power of consumers were above that of workers, this would imply that the firm would give up more to the worker than what it can expect from the sales, and the total surplus would be negative in stage $g$. In the special case where the worker's bargaining weight in the labor market is equal to the consumer's bargaining weight in the goods market, $\alpha_{L}=\alpha_{G}$, the consumption surplus for the firm and the wage no longer depends on the price in the goods market or changes in the marginal revenue from production.

Viability conditions insure that the decentralized equilibrium is not degenerate. The full conditions are easily derived. To summarize these conditions, it is necessary for wages to fall into the interval $\left(x \mathcal{P}-y^{0}, x \mathcal{P}\right)$ where $y^{0}$ is the transfer of numeraire (income) in addition to the labor income. This means that workers can pay for the goods in numeraire and the firm can pay workers above the selling price. This condition is satisfied if the supply of numeraire $\bar{y}^{0}$ is large enough compared to a combination of parameters involving $\alpha_{L}$ and $\alpha_{G}$ as well as $x, z$ and $\theta$. Another condition is that the unemployed workers cannot consume the inelastic supply of the search good $x$, which is the case when $\bar{y}^{0}<x \mathcal{P}=\left(1-\alpha_{G}\right) \Phi x$.

\subsection{Prices and wages under imperfect credit markets}

We now need to establish the setting of wages in order to determine equilibrium labor market tightness.

The prices in all three markets, the repayment to the credit $\psi$, the wage to the worker $w$, and the price for the good $\mathcal{P}$, are derived in the same manner as in the earlier respective subsections. The price equation remains a simple rule, as in the LG model, that is a function of the marginal utility of the search good $\Phi$ :

$$
\text { Price: } \mathcal{P}=\left(1-\alpha_{G}\right) \Phi \text {. }
$$


Wages now incorporate the value of recoverable search costs in the financial markets, $J_{v}=$ $K(\phi)$. Assuming a wage rule where the wage remains constant in stages $g$ and $\pi$, and is negotiated in stage $g$ to satisfy the Nash sharing rule:

$$
\left(1-\alpha_{L}\right)\left(W_{n 0}-W_{u}\right)=\alpha_{L}\left(J_{g}-J_{v}\right)
$$

one obtains a wage equation:

$$
w=\left(1-\alpha_{L}\right)\left(r W_{u}-\overline{y_{0}}\right)-\alpha_{L}\left(r+s^{C}\right) K+\frac{\alpha_{L}-\alpha_{G}}{1-\alpha_{G}} Q_{g}^{\prime} x \mathcal{P}
$$

where $Q_{g}^{\prime}=\lambda /\left(r+s^{C}+s^{L}+s^{G}+\lambda\right)$. Again, the wage converges to CL wage when goods market frictions disappear $(\lambda \rightarrow \infty)$, to the wage in the LG model when financial frictions disappear $(K \rightarrow$ $0)$, and to the conventional Pissarides wage when both goods and financial frictions disappear.

\section{A quantitative exploration of the role of complementarities be- tween the three markets}

We propose in this section to calibrate the CLG model for three European economies that display strong structural differences in terms of the three markets at stake: the United Kingdom, Germany, and Spain. We use data mainly provided by Eurostat which will be described in subsection 5.1. For each country, we run a first calibration targeting 2005 data. Based on the results, some structural parameters are fixed and a second calibration is run with 2014 targets. This allows for a comparison between the three economies at two different points in time, before and after the peak of the financial crisis.

The results obtained will then be used to proceed to different numerical exercises, as described in subsection 5.2. First, we can quantify the relative weight of each type of friction in firms' entry decision in the three countries studied. The model also allows us to analyze the interdependence of the credit, labor, and goods markets. We will in particular focus on the impact of each type of friction on the unemployment rate.

\subsection{Calibration strategy for three countries: Germany, UK, Spain}

The time period is monthly. In each of the frictional markets, we assume matching functions such that: $p(\phi)=\chi_{C} / \sqrt{\phi}, q(\theta)=\chi_{L} / \sqrt{\theta}$, and $\lambda(\xi)=\chi_{G} \sqrt{\xi}=\chi_{G}$. Table 1 summarizes the targets used for the calibration. Table 2 displays the resulting parameter values. We provide more details

on the calibration in Appendix G, and report the values of endogenous variables in Appendix Table A.1 for completeness.

\subsection{Exploring the role of frictions and their interactions}

\subsubsection{Decomposing the three components of entry costs}

Going back to the entry equation, one has in the left-hand side three different blocks, each of them reflecting the intensity of the entry cost due to credit, labor, and goods markets:

$$
\left(1+\frac{r+s^{C}}{q}\right) K+\frac{\gamma}{q}+\frac{1}{1-Q_{\pi} Q_{g}}\left(\frac{w_{g}-s^{L} K}{r+s^{C}+s^{L}+\lambda}\right)=\frac{Q_{g}}{1-Q_{\pi} Q_{g}}\left(\frac{x \mathcal{P}-w_{\pi}+s^{L} K}{r+s^{T}}\right)
$$


Table 1: Calibration targets: monthly frequency

\begin{tabular}{|c|c|c|c|c|c|c|}
\hline Market & Calibration target & Model & Year & UK & SPA & GER \\
\hline \multirow{4}{*}{ Credit } & \multirow{2}{*}{ finance's share in GDP } & \multirow{2}{*}{$\Sigma$} & 2005 & .024 & .016 & .018 \\
\hline & & & 2014 & .025 & .013 & .014 \\
\hline & \multirow{2}{*}{$\begin{array}{l}\text { credit matching rate } \\
\text { search for credit ratio }\end{array}$} & \multirow{2}{*}{$\begin{array}{c}p \\
\kappa_{B} / \kappa_{I}\end{array}$} & 2005 & $1 / 6$ & $1 / 6$ & $1 / 6$ \\
\hline & & & 2005 & 1 & 1 & 1 \\
\hline \multirow{10}{*}{ Labor } & \multirow{2}{*}{ unemployment rate } & \multirow{2}{*}{$\mathcal{U}$} & 2005 & .048 & .092 & .110 \\
\hline & & & 2014 & .062 & .245 & .050 \\
\hline & \multirow{2}{*}{ job finding rate } & \multirow[b]{2}{*}{$f$} & 2005 & .164 & .167 & .064 \\
\hline & & & 2014 & .128 & .070 & .103 \\
\hline & \multirow{2}{*}{ job vacancy rate } & \multirow{2}{*}{$\mathcal{V}$} & 2005 & .022 & .008 & .032 \\
\hline & & & 2014 & .023 & .006 & .029 \\
\hline & \multirow{2}{*}{ wages' share in GDP } & \multirow{2}{*}{$\mathcal{W}_{g d p}$} & 2005 & .578 & .532 & .551 \\
\hline & & & 2014 & .567 & .515 & .567 \\
\hline & \multirow{2}{*}{$\begin{array}{l}\text { ratio unemployment benefits over wages } \\
\text { recruiting costs }\end{array}$} & $z / w$ & 2005 & .24 & .46 & .31 \\
\hline & & $\gamma \mathcal{V} / w$ & 2005 & .036 & .036 & .036 \\
\hline \multirow{4}{*}{ Goods } & \multirow{2}{*}{ ratio of capacity utilization } & \multirow[b]{2}{*}{$\mu_{G}$} & 2005 & .795 & .803 & .840 \\
\hline & & & 2014 & .820 & .757 & .840 \\
\hline & \multirow{2}{*}{ numeraire's share in expenditures } & \multirow{2}{*}{$\mathfrak{N}$} & 2005 & .313 & .336 & .344 \\
\hline & & & 2014 & .323 & .374 & .358 \\
\hline
\end{tabular}

Table 2: Parameter values under monthly calibration

\begin{tabular}{|c|c|c|c|c|c|c|}
\hline & Parameters & & Year & UK & SPA & GER \\
\hline \multirow{7}{*}{ Fixed parameters } & discount rate & $r$ & both & .0033 & .0033 & .0033 \\
\hline & credit separation rate & $s^{C}$ & both & .0028 & .0034 & .0011 \\
\hline & bank's bargaining weight & $\alpha_{C}$ & both & .5 & .5 & .5 \\
\hline & productivity & $x$ & both & 1 & 1 & 1 \\
\hline & quantity of numeraire & $\bar{y}^{0}$ & both & $1 / 12$ & $1 / 12$ & $1 / 12$ \\
\hline & marginal utility of consumption & $\Phi$ & both & 1.15 & 1.15 & 1.15 \\
\hline & pure-taste shock rate & $\tau$ & both & .01 & .01 & .01 \\
\hline \multirow{4}{*}{$\begin{array}{l}\text { Parameters calibrated } \\
\text { to } 2005 \text { and then } \\
\text { kept fixed for } 2014\end{array}$} & credit matching factor & $\chi_{C}$ & both & .17 & .17 & .17 \\
\hline & credit search effort & $\kappa_{I}$ & both & .23 & .29 & .30 \\
\hline & vacancy posting cost & $\gamma$ & both & .23 & .55 & .15 \\
\hline & unemployment benefits & $z$ & both & .034 & .056 & .040 \\
\hline \multirow{12}{*}{ Calibrated parameters } & \multirow{2}{*}{ project screening cost } & \multirow{2}{*}{$\kappa_{B}$} & 2005 & .23 & .29 & .30 \\
\hline & & & 2014 & .22 & .28 & .10 \\
\hline & \multirow{2}{*}{ job separation rate } & \multirow{2}{*}{$s^{L}$} & 2005 & .005 & .014 & .007 \\
\hline & & & 2014 & .006 & .019 & .004 \\
\hline & \multirow{2}{*}{ labor matching factor } & \multirow{2}{*}{$\chi_{L}$} & 2005 & .24 & .57 & .12 \\
\hline & & & 2014 & .21 & .46 & .14 \\
\hline & \multirow{2}{*}{ worker's bargaining weight } & \multirow{2}{*}{$\alpha_{L}$} & 2005 & .88 & .94 & .94 \\
\hline & & & 2014 & .90 & .98 & .90 \\
\hline & \multirow{2}{*}{ goods matching factor } & \multirow{2}{*}{$\chi_{G}$} & 2005 & .11 & .18 & .14 \\
\hline & & & 2014 & .13 & .18 & .12 \\
\hline & \multirow{2}{*}{ consumer's bargaining power } & \multirow{2}{*}{$\alpha_{G}$} & 2005 & .82 & .83 & .84 \\
\hline & & & 2014 & .83 & .81 & .85 \\
\hline
\end{tabular}


Table 3: Measuring the respective role of market frictions in each market: decomposition of the three components of entry costs in 2014

\begin{tabular}{lccccc}
\hline Static decomposition of each block: & & Credit & Labor & Goods & Sum \\
\hline Share of entry costs due to each friction & UK & $51.6 \%$ & $12.4 \%$ & $36.0 \%$ & $100 \%$ \\
in equation $(39)$ & Ger & $41.9 \%$ & $15.8 \%$ & $42.3 \%$ & $100 \%$ \\
& Spa & $80.4 \%$ & $4.3 \%$ & $15.3 \%$ & $100 \%$ \\
\hline Limit cases of an economy with only one friction: & & $C$ model & L model & G model & Sum \\
Size of entry costs in limiting cases relative to total & UK & $50.8 \%$ & $14.5 \%$ & $48.0 \%$ & $113.3 \%$ \\
initial entry costs in equation $(39)$ when $\chi_{j}, \chi_{j^{\prime}} \rightarrow+\infty$ & Ger & $40.9 \%$ & $18.0 \%$ & $51.7 \%$ & $110.7 \%$ \\
in pairs for for $j, j^{\prime}=C, L, G$, and $j \neq j^{\prime}$ & Spa & $80.3 \%$ & $5.3 \%$ & $36.3 \%$ & $121.9 \%$ \\
\hline
\end{tabular}

Note: C (resp. L, G) model refers to an economy with only credit (respectively labor, goods) frictions

This equation also displays some interesting interaction effects between frictions in separate markets. For instance, the degree of labor market frictions amplifies the marginal effect of credit frictions summarized in $K$. Indeed, the lower $q$ is, the higher will be the effect of $K$ on total entry costs, as the cost of credit from longer periods of search in the labor market will increase. Hence, labor frictions impact both in the first term and in the second term of the entry side of the equation. Similarly, since entry wages are determined taking into account costs $K$, as in equation (38), higher financial frictions $K$ reduce future wages. This reduces entry costs associated with goods market frictions (the third entry cost), and therefore leads to a partial substitutability between goods and financial markets.

We can compute the relative weight of each of the three blocks in the total entry costs faced by the firm as follows. In a purely accounting sense, one can attribute to each market the share in costs due respectively to $\left(1+\frac{r+s^{C}}{q}\right) K, \frac{\gamma}{q}$, and $\frac{1}{1-Q_{\pi} Q_{g}}\left(\frac{w_{g}-s^{L} K}{r+s^{C}+s^{L}+\lambda}\right)$. This is illustrated in the first part of Table 3, which reports the market friction's share of total entry costs for each country to which we have calibrated the model. By construction, the sum reaches $100 \%$.

Another exercise gives a slightly similar conclusion but in a less mechanical sense. Indeed, keeping all other parameters constant, the model can be solved in different particular cases where matching efficiency parameters $\chi_{C}, \chi_{L}$, or $\chi_{G}$ tend to infinity (i.e., the corresponding market becomes frictionless). Along the way, the endogenous variables (wages, tightness, and transition rates) also change, themselves affecting the value of each component of the entry costs. For instance, having $\chi_{C}$ and $\chi_{L}$ go simultaneously to infinity leaves only the entry costs due to the initial deficit of firms trying to sell, and focuses on the role of goods market entry costs. Similarly, having $\chi_{L}$ and $\chi_{G}$ go to infinity gives the role of the entry costs due to the credit frictions. In each limiting case the value of the entry cost is compared to the total entry cost from its three components of computed prior to removing the frictions (i.e., the total costs of equation (39)) . The results of this exercise are reported in the lower panel of Table 3. Note that now, by construction, the sum of all columns cannot be $100 \%$. It is actually larger than $100 \%$.

Interestingly, the share of labor market costs is small compared to the share due to the other frictions. In Spain especially, the labor block is of limited importance, while the financial block captures most of the entry cost (just over 80\%). This may be due to the fact that, in 2014, the Spanish economy was more adversely affected by the financial crisis which severely affected banks. The fact that the goods market block is higher in the second part of the table for all countries, and especially Spain, comes from the fact that labor and credit frictions reduced wages overall. Shutting them off leads to a higher entry wage, and therefore magnifies goods market frictions relative to the benchmark case. 


\subsubsection{Demand-side effects: how consumer income shocks affect entry and unemploy- ment}

Another exercise is to attempt to isolate the role of income shocks through the demand for search goods by consumers. In equation (39), this can be seen by observing that in total separations $s^{T}=s^{L}+s^{C}+s^{G}=2 s^{L}+2 s^{C}+\tau$, the terms $s^{C}$ and $s^{L}$ arise twice. This is due to the fact that the corresponding shocks, a separation in the credit market or the labor market, affect profits in two different ways: once directly, as they capture the risk of labor turnover and credit market shocks on the expected revenue of the firm itself; but also a second time indirectly, as these shocks affect consumers through their own firms, leading to a loss of income and the separation of the consumption relation. To decompose the two effects, it is useful to introduce a subscript, $s$, to the turnover shocks for the supply's direct effect on firms. We refer to this as the "classical effect." A demand side effect arise through separations in indicate with the subscript $d$ and summarize in $s^{G}=\tau+s_{d}^{L}+s_{d}^{C}$. We refer to this as the "consumption effect." We thus have, with this new notation:

$$
s^{T}=s_{s}^{L}+s_{s}^{C}+s^{G}=s_{s}^{L}+s_{s}^{C}+\tau+s_{d}^{L}+s_{d}^{C}
$$

The respective role of these two shocks on the firm and on its consumer's income can be explored as follows. First, one can calculate the rise in labor market tightness induced by doubling labor

and credit turnover shocks $s_{k}^{L}, s_{k}^{C}$, for both $k=s, d$, and keeping the rate of change in consumer taste constant $\tau$. The first column in Table 4 calculates the percentage change in labor market tightness from these comparative static exercises. The effect of increasing both turnover rates simultaneously leads to a decrease of equilibrium labor market tightness. In the case of the UK this is a $20.4 \%$ decline, $14.2 \%$ in Germany, and a larger $43.9 \%$ in Spain. The last two columns of Table 4 decompose the effect with a part due to only the supply side, thus maintaining $s^{G}=s_{d}^{L}+s_{d}^{C}+\tau$ fixed, and the residual part where only $s^{G}$ would change. The classical effect is responsible for the largest share of the decline in labor market tightness, ranging between $70 \%$ and $85 \%$ depending on the country. Nonetheless, the demand side effect is a non-negligible component of the effect of turnover on labor market tightness. These reults provide an upper bound on the depressing effect of the lack of consumption sharing in this economy.

\subsubsection{The respective role of each friction on unemployment}

The model in steady state offers comparative statics exercises for the respective role of different frictions. Investigating the impact of each friction separately or simultaneously is likely to deliver different outcomes because of potential complementarities between frictions. As said above, there are both complementarity and substitutability across frictions.

To better understand the pattern of complementarity, we represent in Figure 2 the left-hand side (costs) and the right-hand side (profits) of the entry equation, as a function of labor market tightness, and double the efficiency of the three markets one by one. The solid lines are the entry and profit curves in the benchmark economy. The dashed lines represent the same curve after a doubling of the efficiency of each market separately, respectively credit, labor, and goods market when going from left to right.

It can be seen that the greatest impact on curves is the effect of a change in the efficiency of credit market matching. This shifts entry down, as expected, since a $1 \%$ increase in $\chi_{C}$ reduces $K$ by the same amount, and these costs represent more than $50 \%$ of total entry costs. However, the total effect on labor market tightness is not large. This is because the higher efficiency of matching in the credit market is partly offset by lower future profits, due to higher wages and a lower "recovery value" after labor separation. In contrast, changes in the efficiency of labor markets reduces entry costs as well. This leads to larger increases in labor market tightness, with 
Table 4: Amplification effects of supply shocks through their supplementary impact on consumer's income and demand for goods. Variation in labor market tightness when doubling the separation rates $s^{L}$ and $s^{C}$ individually or in combination.

\begin{tabular}{|c|c|c|c|c|}
\hline & \multirow{4}{*}{\multicolumn{2}{|c|}{$\begin{array}{c}\% \text { change in } \theta \\
\text { when doubling labor } \\
\text { and credit turnover in } \pi \\
k=s, d\end{array}$}} & \multicolumn{2}{|c|}{ Decomposition } \\
\hline & & & \multirow{4}{*}{$\begin{array}{c}\text { Classical effect } \\
\text { Supply driven } \\
k=s \\
0.706\end{array}$} & \multirow{4}{*}{$\begin{array}{c}\text { Consumption effect } \\
\text { Demand driven } \\
k=d\end{array}$} \\
\hline & & & & \\
\hline & & & & \\
\hline \multirow{3}{*}{ UK } & $s_{k}^{L} \times 2$ & $-11.6 \%$ & & \\
\hline & $s_{k}^{C} \times 2$ & $-9.8 \%$ & 0.821 & 0.179 \\
\hline & $s_{k}^{C}, s_{k}^{L} \times 2$ & $-20.4 \%$ & 0.772 & 0.228 \\
\hline \multirow{3}{*}{ Germany } & $s_{k}^{L} \times 2$ & $-10.2 \%$ & 0.719 & 0.281 \\
\hline & $s_{k}^{C} \times 2$ & $-4.5 \%$ & 0.825 & 0.175 \\
\hline & $s_{k}^{C}, s_{k}^{L} \times 2$ & $-14.2 \%$ & 0.758 & 0.242 \\
\hline \multirow{3}{*}{ Spain } & $s_{k}^{L} \times 2$ & $-36.1 \%$ & 0.806 & 0.194 \\
\hline & $s_{k}^{C} \times 2$ & $-11.3 \%$ & 0.853 & 0.147 \\
\hline & $s_{k}^{C}, s_{k}^{L} \times 2$ & $-43.9 \%$ & 0.830 & 0.170 \\
\hline
\end{tabular}

Classical effect: contribution of supply driven separations, keeping demand driven separations $s^{G}=s_{d}^{L}+s_{d}^{C}+\tau$ fixed. Consumption effect: contribution of demand driven separations, keeping supply driven separations $s_{s}^{L}, s_{s}^{C}$ fixed.

no impact on the profit curve. Finally, an increase in the efficiency of goods market matching has both a downward effect on costs and an ambiguous effect on profits as part of the effect appears in wages. However, the latter effect is small and, overall, the main effect is to increase labor market tightness as well. 
Table 5: Percentage (log-variation) in $\theta$ from changes in matching efficiency

\begin{tabular}{|c|c|c|c|c|c|c|c|c|c|c|c|c|}
\hline \multirow[b]{2}{*}{$\% \Delta \chi_{j}, j=C, L, G:$} & \multicolumn{4}{|l|}{ UK } & \multicolumn{4}{|c|}{ Germany } & \multicolumn{4}{|l|}{ Spain } \\
\hline & +10 & +33 & +50 & +100 & +10 & +33 & +50 & +100 & +10 & +33 & +50 & +100 \\
\hline \multicolumn{13}{|c|}{ One parameter increases } \\
\hline$\frac{\Delta \theta}{\Delta \chi_{C}}$ & 8.6 & 7.9 & 7.5 & 6.6 & 7.0 & 6.4 & 6.0 & 5.3 & 7.6 & 6.9 & 6.6 & 5.8 \\
\hline$\frac{\Delta \chi_{C}}{\Delta \chi_{L}}$ & 9.3 & 8.4 & 8.0 & 7.0 & 8.5 & 7.7 & 7.3 & 6.4 & 30.5 & 27.8 & 26.3 & 23.1 \\
\hline$\frac{\Delta \theta}{\Delta \chi_{G}}$ & 20.1 & 18.6 & 17.7 & 15.7 & 17.3 & 15.9 & 15.2 & 13.5 & 30.5 & 28.3 & 27.0 & 24.1 \\
\hline \multicolumn{13}{|c|}{ Two parameters increase: complementarities } \\
\hline$\frac{\Delta^{2} \theta}{\Delta \chi_{C} \Delta \chi_{L}}$ & -4.6 & -4.0 & -3.8 & -3.3 & -4.7 & -3.6 & -3.5 & -3.1 & -12.9 & -11.9 & -11.4 & -10.1 \\
\hline$\frac{\Delta^{2} \theta}{\Delta \chi_{C} \Delta \chi_{G}}$ & -4.6 & -4.1 & -3.9 & -3.4 & -3.4 & -2.5 & -2.3 & -2.0 & -12.8 & -11.7 & -11.0 & -9.7 \\
\hline$\frac{\Delta^{2} \theta}{\Delta \chi_{L} \Delta \chi_{G}}$ & -9.5 & -8.8 & -8.4 & -7.5 & -8.2 & -7.6 & -7.3 & -6.5 & -12.9 & -12.0 & -11.5 & -10.3 \\
\hline
\end{tabular}

Table 6: Unemployment rate effect of increase in matching efficiency

\begin{tabular}{|c|c|c|c|c|c|c|c|c|c|c|c|c|}
\hline \multirow{2}{*}{$\begin{array}{l}\text { Baseline rate } \\
{[-0.075 \mathrm{in}]} \\
\% \Delta \chi_{j} \\
j=C, L, G:\end{array}$} & \multicolumn{4}{|c|}{ UK: 6.2} & \multicolumn{4}{|c|}{ Germany: 5.0} & \multicolumn{4}{|c|}{ Spain: 24.5} \\
\hline & +10 & +33 & +50 & +100 & +10 & +33 & +50 & +100 & +10 & +33 & +50 & +100 \\
\hline$\chi_{C}$ & 6.2 & 6.1 & 6.1 & 6.0 & 4.9 & 4.9 & 4.9 & 4.9 & 24.4 & 24.3 & 24.2 & 24.1 \\
\hline$\chi_{L}$ & 5.6 & 4.7 & 4.1 & 3.1 & 4.5 & 3.7 & 3.3 & 2.5 & 22.5 & 19.0 & 17.0 & 13.0 \\
\hline$\chi_{G}$ & 6.1 & 6.0 & 6.0 & 5.9 & 4.9 & 4.9 & 4.8 & 4.7 & 24.2 & 23.7 & 23.5 & 22.9 \\
\hline$\chi_{C}, \chi_{L}$ & 5.6 & 4.6 & 4.1 & 3.0 & 4.5 & 3.7 & 3.3 & 2.4 & 22.4 & 18.8 & 16.8 & 12.8 \\
\hline$\chi_{L}, \chi_{G}$ & 5.6 & 4.5 & 4.0 & 3.0 & 4.5 & 3.7 & 3.2 & 2.4 & 22.2 & 18.4 & 16.3 & 12.1 \\
\hline$\chi_{C}, \chi_{G}$ & 6.1 & 6.0 & 5.9 & 5.7 & 4.9 & 4.8 & 4.8 & 4.7 & 24.1 & 23.5 & 23.2 & 22.6 \\
\hline$\chi_{C}, \chi_{L}, \chi_{G}$ & 5.6 & 4.5 & 3.9 & 2.9 & 4.5 & 3.6 & 3.2 & 2.3 & 22.2 & 18.2 & 16.1 & 12.0 \\
\hline
\end{tabular}



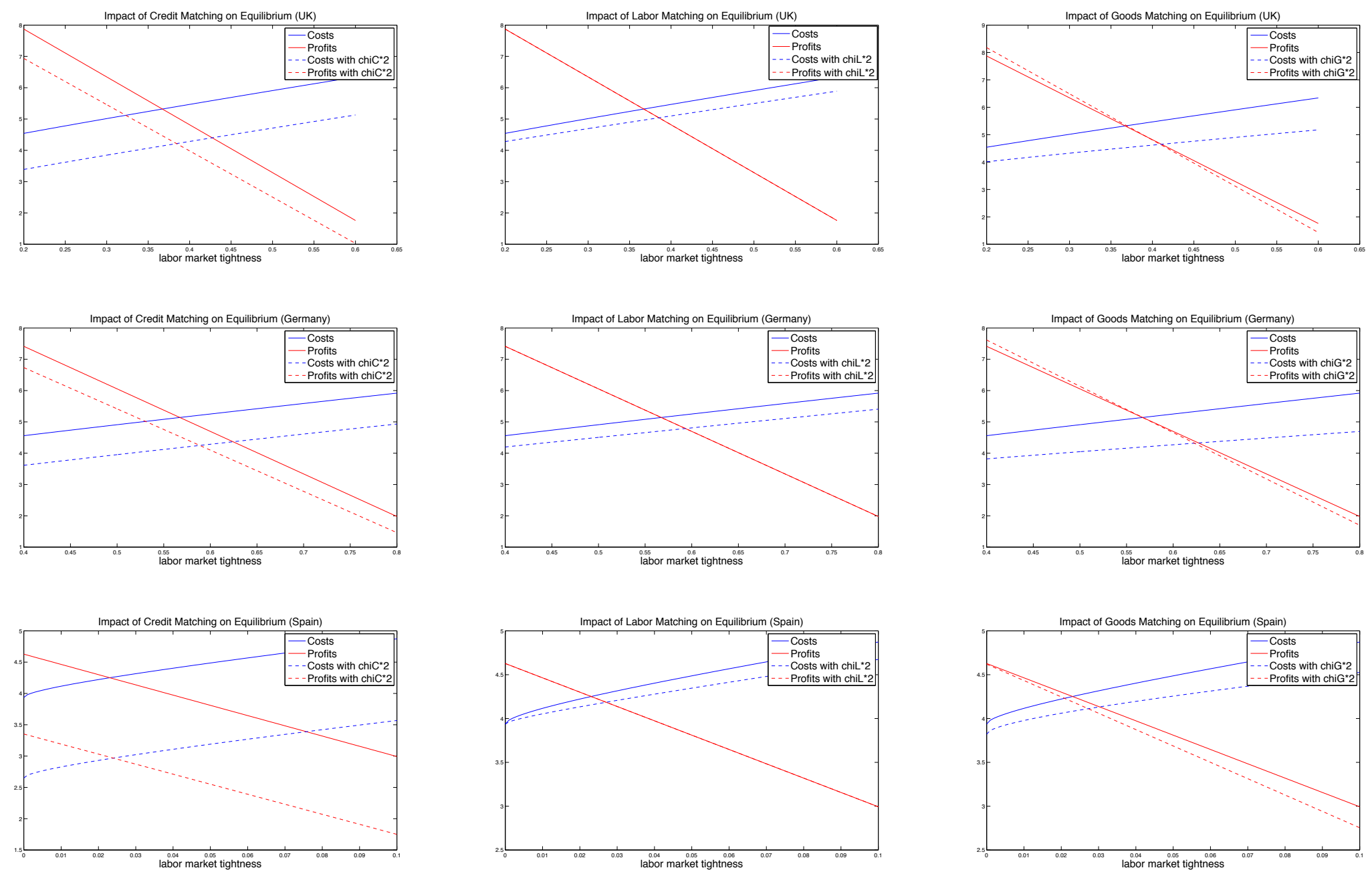

Figure 2: Effect of doubling each matching efficiency parameter $\chi_{j}, j=C, L, G$ on the entry costs curve and the profit curve as a function of labor market tightness. Left charts: doubling credit matching efficiency; middle charts: doubling labor matching efficiency; right charts: doubling goods matching efficiency. 
Table 5 shows the effects of varying matching efficiency on labor market tightness. The slope of this effect varies across countries, but a $10 \%$ increase in matching efficiency in credit market raises tightness by $8.6 \%$ in the UK, $7 \%$ in Germany, and $7.6 \%$ in Spain (implying elasticities of respectively $0.86,0.7$, and 0.76 ). Note that this effect declines with the size of the efficiency increase. Similarly, a 10\% increase in matching efficiency in labor market raises tightness by $9.3 \%$ in the UK, 8.5\% in Germany, and a larger 30.5\% in Spain (implying elasticities of respectively $0.93,0.85$, and 3.05 ). Finally, an increase in goods market efficiency generates an increase in labor market tightness of $20.1 \%, 17.3 \%$, and $30.5 \%$ (implying elasticities of respectively $2.01,1.73$, and 3.05). Larger elasticities correspond to the case of smaller total surplus (especially for Spain) and the friction considered having a greater impact on that surplus; with small surpluses, the economy is more volatile to shocks. Note also that cross-market effects tend to attenuate each other: lower frictions in one market reduce the marginal impact of reducing frictions in another market. This effect comes from the wage effect of frictions. Higher efficiency of matching raises wages through both lower $K$ and higher $\theta$, and the second order derivatives of $\theta$ to two frictions is negative. In the case of fixed wages, one would have instead $\frac{\Delta^{2} \theta}{\Delta \chi_{C} \Delta \chi_{L}}=\frac{\Delta^{2} \theta}{\Delta \chi_{G} \Delta \chi_{L}}=0$, while elasticities of labor market tightness to efficiency of matching is typically 10 times higher, an effect well known in the literature following Shimer (2005) and Hall (2005).

Finally, and as expected from the graphics in Figure 2, the main effect on unemployment reported in Table 6 comes from reducing labor market frictions, despite the potentially larger impact of credit market frictions: reducing credit market frictions pushes entry cost down on the credit side, but the rise in wages mitigates this effect and ex-post turns out to almost eliminate the gains. In particular, in the UK, doubling the efficiency of goods and credit markets would reduce the rate of unemployment by 3.1 percentage points. In Germany, the effect would be 2.5 percentage points. In Spain the effect would be 11.5 percentage points.

\subsection{Robustness to variations in targets or in fixed parameters}

The robustness of our results is tested in varying (over sometimes large ranges) the parameters for which we either have no target in the data or uncertain targets.

Table 7 shows the decomposition of the three entry costs to, respectively from top to bottom, a doubling or a division by ten of the share of finance (business sector) in GDP ${ }^{4}$; a doubling or a division by 2 of the relative costs of credit search of creditors relative to projects/firms; a doubling or a division by 2 of the transition rate of projects/firms from search for credit to the labor stage; a change of the bargaining power of creditors vis-à-vis the firm to 0.9 or 0.2 ; a doubling or a division by 2 of the exogenous injections of Lucas fruits into the economy, and; finally a change in the marginal utility of search goods by 10 or $20 \%$. As is apparent, changes in the decomposition are rarely important compared to the benchmark case. In some cases, they are even totally neutralized in the entry equation by proportional comovements of the three components, as is the case for instance in the last row for changes in the marginal utility of search goods, or in other rows, for instance that on varying the duration of credit search $1 / p$. The same conclusion is reached when replicating the decomposition exercise reported in the lower part of Table 3, consisting on letting frictions disappear in individual markets two-by-two to recalculate these shares. See Table A.2 in the Appendix for the detailed results.

\footnotetext{
${ }^{4}$ We had attributed half of the total finance share to the business sector, the other half being, in national accounts, services to consumers. This is close to the division for U.S. data but not necessarily applicable to the countries studied here. Note that reducing the value added of the financial sector relative to GDP raises the prospection costs in the calibration when $\alpha_{C}$ is fixed. Doing so reduces the profit margins of the financial sector, which in turn raises the share of credit in total entry costs.
} 
Table 7: Robustness of the decomposition in terms of the share of entry costs

\begin{tabular}{|c|c|c|c|c|c|c|c|c|c|c|c|c|}
\hline \multirow[b]{2}{*}{ Friction: } & \multicolumn{4}{|l|}{ UK } & \multicolumn{4}{|c|}{ Germany } & \multicolumn{4}{|c|}{ Spain } \\
\hline & $\mathrm{C}$ & $\mathrm{L}$ & $\mathrm{G}$ & Sum & $\mathrm{C}$ & $\mathrm{L}$ & $\mathrm{G}$ & Sum & $\mathrm{C}$ & $\mathrm{L}$ & G & Sum \\
\hline Benchmark & 51.6 & 12.4 & 36.0 & 100 & 41.9 & 15.8 & 42.3 & 100 & 80.4 & 4.3 & 15.3 & 100 \\
\hline \multicolumn{13}{|c|}{ Finance's share in GDP } \\
\hline$\Sigma \times 2$ & 45.9 & 13.2 & 40.9 & 100 & 34.4 & 17.4 & 48.2 & 100 & 78.1 & 4.8 & 17.2 & 100 \\
\hline$\Sigma / 10$ & 56.6 & 11.5 & 31.9 & 100 & 47.5 & 14.5 & 38.0 & 100 & 82.7 & 3.8 & 13.5 & 100 \\
\hline \multicolumn{13}{|c|}{ Credit-search costs } \\
\hline$\kappa_{B}=2 \kappa_{I}$ & 51.6 & 12.4 & 36.0 & 100 & 41.9 & 15.8 & 42.3 & 100 & 80.4 & 4.3 & 15.3 & 100 \\
\hline$\kappa_{B}=\kappa_{I} / 2$ & 51.6 & 12.4 & 36.0 & 100 & 41.8 & 15.8 & 42.4 & 100 & 80.4 & 4.3 & 15.3 & 100 \\
\hline \multicolumn{13}{|c|}{ Credit finding rate } \\
\hline$p \times 2$ & 51.6 & 12.4 & 36.0 & 100 & 41.9 & 15.8 & 42.3 & 100 & 80.4 & 4.3 & 15.3 & 100 \\
\hline$p / 2$ & 51.6 & 12.4 & 36.0 & 100 & 41.8 & 15.8 & 42.4 & 100 & 80.4 & 4.3 & 15.3 & 100 \\
\hline \multicolumn{13}{|c|}{ Creditor's bargaining power } \\
\hline$\alpha_{C}=0.8$ & 51.3 & 12.4 & 36.3 & 100 & 41.1 & 15.6 & 43.3 & 100 & 80.9 & 4.2 & 15.0 & 100 \\
\hline$\alpha_{C}=0.2$ & 50.5 & 12.5 & 37.0 & 100 & 41.5 & 16.2 & 42.3 & 100 & 78.9 & 4.7 & 16.4 & 100 \\
\hline \multicolumn{13}{|c|}{ Quantity of numeraire } \\
\hline $\bar{y}^{0} \times 2$ & 51.7 & 12.4 & 35.8 & 100 & 42.3 & 15.8 & 41.9 & 100 & 80.4 & 4.3 & 15.2 & 100 \\
\hline $\bar{y}^{0} / 2$ & 50.7 & 12.5 & 36.8 & 100 & 35.9 & 16.9 & 47.2 & 100 & 80.3 & 4.4 & 15.4 & 100 \\
\hline \multicolumn{13}{|c|}{ Marginal utility of search good } \\
\hline$\Phi=1.2$ & 51.6 & 12.4 & 36.0 & 100 & 41.9 & 15.8 & 42.3 & 100 & 80.4 & 4.3 & 15.3 & 100 \\
\hline$\Phi=1.1$ & 51.6 & 12.4 & 36.0 & 100 & 41.9 & 15.8 & 42.3 & 100 & 80.4 & 4.3 & 15.3 & 100 \\
\hline
\end{tabular}




\section{Conclusion}

This paper has proposed a simplified structure of complex economies with imperfect credit, labor, and goods markets. We have shown how to solve them in the steady state with a rich structure of bargaining over prices, wages, and financial repayment, and in the presence of turnover rates specific to each phase of the firm, thus generalizing our previous approach (Petrosky-Nadeau and Wasmer (2015)). We then apply this model by calibrating it to three European economies.

We find that, for these countries, goods and credit market frictions are a dominant share of entry costs. They deserve much more attention in the quantitative macroeconomic literature, a point similar to that in Pissarides (2009) where noncyclical entry costs were shown to considerably improve the fit of the search and matching model to US data. We also find that demand side effects, through individual income shocks that affect the demand for goods, are not extremely important, although positive. They account for at most 15 to $25 \%$ of the effect of job destruction shocks on aggregate labor market tightness. We finally find that the speed of matching in the goods market and the credit market represent small margins of improvement in the level of unemployment. Most of the improvement comes from the speed of matching in the labor market.

The general conclusion is that the benchmark matching model in the labor market is a good approximation of the first-order determinants of unemployment, even though it necessarily misses the main component of firms' entry costs. Richer models of the CLG type considerably improve our quantitative understanding of the labor market equilibrium. 


\section{References}

Bai, Y., Rios-Rull, V., and Storesletten, K. (2011). Demand shocks that look like productivity shocks. Mimeo University of Minnesota.

Bethune, Z., Rocheteau, G., and Rupert, P. (2015). Aggregate Unemployment and Household Unsecured Debt. Review of Economic Dynamics, 18(1):77-100.

Branch, W. A., Petrosky-Nadeau, N., and Rocheteau, G. (2015). Financial frictions, the housing market, and unemployment. Journal of Economic Theory, forthcoming.

Brzustowski, T. (2015). Unemployment in Europe: a model with three frictional markets. Master's thesis, Ecole Polytechnique.

Diamond, P. A. (1971). A model of price adjustment. Journal of Economic Theory, 3(2):156-168.

Diamond, P. A. (1982). Aggregate demand management in search equilibrium. Journal of Political Economy, 90(5):pp. 881-894.

Gertler, M. and Trigari, A. (2009). Unemployment Fluctuations with Staggered Nash Wage Bargaining. Journal of Political Economy, 117(1):38-86.

Hall, R. E. (2005). Employment fluctuations with equilibrium wage stickiness. American Economic Review, 95(1):50-65.

Hall, R. E. (2012). The cyclical response of advertising refutes counter-cyclical profit margins in favor of product-market frictions. NBER Working Papers 18370, National Bureau of Economic Research, Inc.

Kaplan, G. and Menzio, G. (2013). Shopping Externalities and Self-Fulfilling Unemployment Fluctuations. NBER Working Papers 18777, National Bureau of Economic Research, Inc.

Lagos, R. and Wright, R. (2005). A unified framework for monetary theory and policy analysis. Journal of Political Economy, 113(3):pp. 463-484.

Lehmann, E. and Van der Linden, B. (2010). Search frictions on product and labor markets: Money in the matching function. Macroeconomic Dynamics, 14(1):56-92.

Michaillat, P. and Saez, E. (2014). An Economical Business-Cycle Model. NBER Working Papers 19777, National Bureau of Economic Research, Inc.

Nosal, E. and Rocheteau, G. (2011). Money, Payments, and Liquidity, volume 1 of MIT Press Books. The MIT Press.

Petrosky-Nadeau, N. and Wasmer, E. (2015). Macroeconomic dynamics in a model of goods, labor, and credit market frictions. Journal of Monetary Economics, 72(C):97-113.

Petrosky-Nadeau, N., Wasmer, E., and Zeng, S. (2015). Shopping Time.

Pissarides, C. A. (2000). Equilibrium unemployment theory. The MIT press.

Pissarides, C. A. (2009). The unemployment volatility puzzle: Is wage stickiness the answer? Econometrica, 77(5):1339-1369.

Shimer, R. (2005). The cyclical behavior of equilibrium unemployment and vacancies. American Economic Review, 95(1):25-49. 
Silva, J. I. and Toledo, M. (2009). Labor turnover costs and the cyclical behavior of vacancies and unemployment. Macroeconomic Dynamics, 13:76-96.

Wasmer, E. (2009). A steady-state model of a non-walrasian economy with three imperfect markets. Discussion Paper 2011-5758, IZA.

Wasmer, E. and Weil, P. (2004). The macroeconomics of labor and credit market imperfections. American Economic Review, 94(4):944-963. 


\section{Appendix}

\section{A Demand and supply of numeraire}

The unemployed can transform part or all their leisure endowment $z$ into additional production of the numeraire. This fixes the demand and supply of the numeraire. Denote by $d z$ this fraction transformed into numeraire, where $d$ might be smaller or larger than 1 (in the latter case the unemployed would enjoy negative leisure, that is exert more effort than the employed workers). They therefore supply $z d+\bar{y}^{0}$ units of good 0 , and receive in turn a flow utility $v\left(0, \bar{y}^{0}+z d, z(1-d)\right)$. Under the additional assumption that leisure and consumption of good 0 are additively separable in the utility function, the value of $d$ is irrelevant hereafter in the utility of the unemployed. However, as shown below, this value matters to equalize the demand and supply of numeraire.

Since it is assumed there is no saving or pooling of income across individuals, a consumer not matched with a search good spends his disposable income denoted by $w$ on the numeraire. Thus $c_{U}^{0}=w+\bar{y}^{0}$. Matched consumers must sacrifice some consumption of the essential good in order to buy the search good. Thus the consumption of good 0 of a matched consumer is $c_{M}^{0}=c_{U}^{0}-\mathcal{P} x=\bar{y}^{0}+w-\mathcal{P} x$.

We denote by $C^{1}=x \mathcal{D}_{M}$ the aggregate consumption of search goods 1 . The aggregate consumption of good 0 is given by

$$
C^{0}=\left(\mathcal{U}+\mathcal{D}_{U}\right) \bar{y}^{0}+\mathcal{D}_{U} w+\mathcal{D}_{M}\left(\bar{y}^{0}+w-\mathcal{P} x\right) .
$$

It is the sum of individual consumption of the unemployed, of the unmatched consumers, and of the matched consumers. The above equation implies that the supply of numeraire $z d \mathcal{U}+\bar{y}^{0}$ equals its demand. Using $\mathcal{U}+\mathcal{D}_{U}+\mathcal{D}_{M}=1$, the equality implies $\mathcal{D}_{U} w+\mathcal{D}_{M}(w-\mathcal{P} x)=z d \mathcal{U}$ or equivalently

$$
\mathcal{N} w-\mathcal{D}_{M} \mathcal{P} x=z d \mathcal{U} .
$$

This equation states that the revenue from firms net of expenses into the search good are spent into the supplementary numeraire provided by the transformation of leisure of the unemployed. Therefore, $d$ adjusts here to equalize demand and supply of numeraire. It is important to note that, once the fraction $d$ of leisure transformed into numeraire to equalize demand and supply is determined, its value disappears from the rest of the model. Only $z$ will affect the equilibrium wages and therefore labor market tightness.

\section{B The general entry equation}

We have the fundamental Bellman equations:

$$
\begin{aligned}
& r E_{c}=-\kappa_{I}+p(\phi)\left(E_{v}-E_{c}\right) \\
& r E_{v}=-\gamma+\gamma+q\left(E_{g}-E_{v}\right)+s^{C v}\left(E_{c}-E_{v}\right) \\
& r E_{g}=-w_{g}+w_{g}+\lambda\left(E_{\pi}-E_{g}\right)+s^{C g}\left(E_{c}-E_{g}\right)+s^{L g}\left(E_{v}-E_{g}\right) \\
& r E_{\pi}=x \mathcal{P}-w_{\pi}-\psi+s^{C \pi}\left(E_{c}-E_{\pi}\right)+s^{G}\left(E_{g}-E_{\pi}\right)+s^{L \pi}\left(E_{v}-E_{\pi}\right)
\end{aligned}
$$

and

$$
\begin{aligned}
& r B_{c}=-\kappa_{B}+\phi p(\phi)\left(B_{v}-B_{c}\right) \\
& r B_{v}=-\gamma+q\left(B_{g}-B_{v}\right)+s^{C v}\left(B_{c}-B_{v}\right) \\
& r B_{g}=-w_{g}+\lambda\left(B_{\pi}-B_{g}\right)+s^{C g}\left(B_{c}-B_{g}\right)+s^{L g}\left(B_{v}-B_{g}\right) \\
& r B_{\pi}=\psi+s^{C \pi}\left(B_{c}-B_{\pi}\right)+s^{G}\left(B_{g}-B_{\pi}\right)+s^{L \pi}\left(B_{v}-B_{\pi}\right)
\end{aligned}
$$

Summing up two-by-two, one obtains the value in the text:

$$
\begin{aligned}
\left(r+s^{C v}\right) J_{v} & =-\gamma+q(\theta)\left(J_{g}-J_{v}\right) \\
\left(r+s^{C g}\right) J_{g} & =-w_{g}+s^{L g}\left(J_{v}-J_{g}\right)+\lambda\left(J_{\pi}-J_{g}\right) \\
\left(r+s^{C \pi}\right) J_{\pi} & =x \mathcal{P}-w_{\pi}+s^{L \pi}\left(J_{v}-J_{\pi}\right)+s^{G}\left(J_{g}-J_{\pi}\right)
\end{aligned}
$$


Two convenient notations can be introduced: let

$$
Q_{g}=\frac{\lambda}{r+s^{L g}+s^{C g}+\lambda} \quad ; \quad Q_{\pi}=\frac{s^{G}}{r+s^{L \pi}+s^{C \pi}+s^{G}}
$$

which allows to rewrite equations (49) and (50) as:

$$
\begin{aligned}
J_{g} & =\left(\frac{s^{L g} K-w_{g}}{\lambda}+J_{\pi}\right) Q_{g} \\
J_{\pi} & =\left(\frac{x \mathcal{P}-w_{\pi}+s^{L \pi} K}{s^{G}}+J_{g}\right) Q_{\pi} .
\end{aligned}
$$

Solutions follow: one has then

$$
\begin{aligned}
& J_{g}=\left[\frac{s^{L g} K-w_{g}}{\lambda}+\left(\frac{x \mathcal{P}-w_{\pi}+s^{L \pi} K}{s^{G}}+J_{g}\right) Q_{\pi}\right] Q_{g} \\
& J_{\pi}=\left[\frac{x \mathcal{P}-w_{\pi}+s^{L \pi} K}{s^{G}}+\left(\frac{s^{L g} K-w_{g}}{\lambda}+J_{\pi}\right) Q_{g}\right] Q_{\pi}
\end{aligned}
$$

or after simplification:

$$
\begin{aligned}
& J_{g}=\frac{Q_{g}}{1-Q_{\pi} Q_{g}} \quad\left[\frac{s^{L g} K-w_{g}}{\lambda}+\left(\frac{x \mathcal{P}-w_{\pi}+s^{L \pi} K}{s^{G}}\right) Q_{\pi}\right] \\
& J_{\pi}=\frac{Q_{\pi}}{1-Q_{\pi} Q_{g}} \quad\left[\frac{x \mathcal{P}-w_{\pi}+s^{L \pi} K}{s^{G}}+\left(\frac{s^{L g} K-w_{g}}{\lambda}\right) Q_{g}\right] .
\end{aligned}
$$

Equation (48) combined with free-entry $J_{v}=K$ immediately delivers:

$$
\begin{aligned}
& \left(1+\frac{r+s^{C v}}{q}\right) K+\frac{\gamma}{q}=J_{g} \\
& \left(1+\frac{r+s^{C v}}{q}\right) K+\frac{\gamma}{q}=\frac{Q_{g}}{1-Q_{\pi} Q_{g}}\left[\frac{s^{L g} K-w_{g}}{\lambda}+\left(\frac{x \mathcal{P}-w_{\pi}+s^{L \pi} K}{s^{G}}\right) Q_{\pi}\right] .
\end{aligned}
$$

Equation (58) can be rewritten by putting entry costs including early wages $w_{g}$ on the left-hand side and rearranging it, so as to have:

$$
\begin{aligned}
& \left(1+\frac{r+s^{C v}}{q}\right) K+\frac{\gamma}{q} \quad+\frac{Q_{g}}{1-Q_{\pi} Q_{g}}\left(\frac{w_{g}-s^{L g} K}{\lambda}\right)=\frac{Q_{g} Q_{\pi}}{1-Q_{\pi} Q_{g}}\left(\frac{x \mathcal{P}-w_{\pi}+s^{L \pi} K}{s^{G}}\right) \\
& \text { or }\left(1+\frac{r+s^{C v}}{q}\right) K+\frac{\gamma}{q}+\frac{1}{1-Q_{\pi} Q_{g}}\left(\frac{w_{g}-s^{L g} K}{r+s^{L g}+s^{C g}+\lambda}\right)=\frac{Q_{g}}{1-Q_{\pi} Q_{g}}\left(\frac{x \mathcal{P}-w_{\pi}+s^{L \pi} K}{r+s^{L \pi}+s^{C \pi}+s^{G}}\right) \\
& \text { or finally } K+Q_{v} \frac{\gamma}{q} \quad+\frac{Q_{v} Q_{g}}{1-Q_{\pi} Q_{g}}\left(\frac{w_{g}-s^{L g} K}{\lambda}\right)=\frac{Q_{v} Q_{g} Q_{\pi}}{1-Q_{\pi} Q_{g}}\left(\frac{x \mathcal{P}-w_{\pi}+s^{L \pi} K}{s^{G}}\right) \\
& \text { with } \\
& Q_{g}=\frac{\lambda}{r+s^{L g}+s^{C g}+\lambda} ; \quad Q_{\pi}=\frac{s^{G}}{r+s^{L \pi}+s^{C \pi}+s^{G}} ; \quad Q_{v}=\frac{q}{r+s^{C v}+q} .
\end{aligned}
$$

\section{Stock-flow equations in the extensive margin CLG model}

In this part, we assume from the start the existence of credit shocks leading to the destruction of the firm in stages $g$ and $\pi$. The stock of firms in stage $\pi$ receives the matches created in the goods market $\lambda \mathcal{N}_{g}$ and loses the firms in stage $\pi$, losing their workers $s^{L \pi} \mathcal{N}_{\pi}$, the consumers quitting the good $s^{G} \mathcal{N}_{\pi}$ and finally the firms destroyed by credit shocks $s^{C} \mathcal{D}_{M}$. The stock of firms in stage $g$ receives the hirings $\mathcal{M}_{L}$ 
and the firms losing their clients $s^{G} \mathcal{N}_{\pi}$, and loses the matches created in the goods market $\lambda \mathcal{N}_{g}$ and loses the firms in stage $g$ losing their workers $s^{L g} \mathcal{N}_{g}$ as well as those hit by a credit shock $s^{C g} \mathcal{N}_{g}$.

The stock of matched consumers receives the matches created in the goods market $\lambda \mathcal{D}_{U}$, loses the matched consumers who lost their job $s^{L g, \pi} \mathcal{D}_{M}$ which occurs either with probability $s^{L g}$ or $s^{L \pi}$ depending on whether the consumer is himself/herself in a firm in stage $g$ or $\pi$ selling (hence the compact notation $s^{L g, \pi}=s^{L g} \mathcal{N}_{g}+s^{L \pi} \mathcal{N}_{\pi} /\left(\mathcal{N}_{g}+\mathcal{N}_{\pi}\right)$ for the expected turnover rate in stage g) and loses the consumers whose firm lost their worker $s^{L} \mathcal{D}_{M}=\left(s^{G}-\tau\right) \mathcal{D}_{M}$; and loses the consumers who changed taste $\tau \mathcal{D}_{M}$. The stock of unmatched consumers loses the matches created in the goods market $\check{\lambda} \mathcal{D}_{U}$, gains the matches created in the labor market $\mathcal{M}_{L}$, gains the consumers whose firm lost their worker $s^{L} \mathcal{D}_{M}$ and loses the unmatched consumers who lost their job $s^{L g, \pi} \mathcal{D}_{U}$ and gains the consumers who changed taste $\tau \mathcal{D}_{M}$. Finally, the pool of unemployed workers loses the matches creates in the labor market $\mathcal{M}_{L}$, gains the job losses $s^{L g, \pi}(1-\mathcal{U})$ which arise, from the firm side, from firms in stage $\pi$ losing their workers $s^{L} \mathcal{N}_{\pi}$ and firms in stage g losing their workers $s^{L} \mathcal{N}_{g}$; or from matched consumers losing their job $s^{L} \mathcal{D}_{M}$ or from unmatched consumers losing their job $s^{L} \mathcal{D}_{U}$ :

$$
\begin{aligned}
& \frac{\partial \mathcal{N}_{\pi}}{\partial t}=\underbrace{\lambda \mathcal{N}_{g}}_{\text {matches G }}-\underbrace{s^{L \pi} \mathcal{N}_{\pi}}_{\text {loss workers }}-\underbrace{s^{G \pi} \mathcal{N}_{\pi}}_{\text {loss customer }}-\underbrace{s^{C \pi} \mathcal{N}_{\pi}}_{\text {credit shock }} \\
& \frac{\partial \mathcal{N}_{g}}{\partial t}=\underbrace{\mathcal{M}_{L}(\mathcal{U}, \mathcal{V})}+\underbrace{s^{G} \mathcal{N}_{\pi}}-\underbrace{\lambda \mathcal{N}_{g}}-\underbrace{s^{L g} \mathcal{N}_{g}}-\underbrace{s^{C g} \mathcal{N}_{g}} \\
& \text { matches L loss customer matches G loss workers credit shock } \\
& \frac{\partial \mathcal{D}_{M}}{\partial t}=\underbrace{\check{\lambda} \mathcal{D}_{U}}_{\text {matches } \mathrm{G}}-\underbrace{s^{L \pi} \mathcal{D}_{M}}_{\text {seller looses worker }}-\underbrace{\underbrace{C \pi} \mathcal{D}_{M}}_{\text {seller hit by a credit shock }}-\underbrace{s^{L g, \pi} \mathcal{D}_{M}}_{\text {matched consumer loses job }} \\
& \underbrace{\tau \mathcal{D}_{M}}_{-} \\
& \text {matched consumer changes tastes } \\
& \frac{\partial \mathcal{D}_{U}}{\partial t}=\underbrace{-\check{\lambda} \mathcal{D}_{U}}_{\text {matches } \mathrm{G}}+\underbrace{\tau \mathcal{D}_{M}}_{\text {matched consumer changed tastes }}+\underbrace{\mathcal{M}_{L}(\mathcal{U}, \mathcal{V})}_{\text {matches L }}+\underbrace{s^{L \pi} \mathcal{D}_{M}}_{\text {seller looses worker }} \\
& +\quad \underbrace{s^{C \pi} \mathcal{D}_{M}} \quad-\quad \underbrace{s^{L g, \pi} \mathcal{D}_{U}} \\
& \text { seller hit by a credit shock unmatched consumer loses job } \\
& \begin{aligned}
\frac{\partial \mathcal{U}}{\partial t} & =-\mathcal{M}_{L}(\mathcal{U}, \mathcal{V})+\left(s^{L g, \pi}+s^{C g, \pi}\right)(1-\mathcal{U})=-\mathcal{M}_{L}(\mathcal{U}, \mathcal{V})+\left(s^{L \pi}+s^{C \pi}\right)\left(\mathcal{N}_{\pi}+\mathcal{N}_{g}\right) \\
& =-\mathcal{M}_{L}(\mathcal{U}, \mathcal{V})+\left(s^{L g, \pi}+s^{C g, \pi}\right)\left(\mathcal{D}_{M}+\mathcal{D}_{U}\right)
\end{aligned}
\end{aligned}
$$

One can easily verify that $\partial \mathcal{N}_{\pi} / \partial t+\partial \mathcal{N}_{g} / \partial t+\partial \mathcal{U} / \partial t=0$ and that $\partial \mathcal{D}_{M} / \partial t+\partial \mathcal{D}_{U} / \partial t+\partial \mathcal{U} / \partial t=0$ at the same time.

\section{Price determination in CLG}

Start from

$$
\begin{aligned}
\left(r+s^{C \pi}\right) J_{\pi} & =x \mathcal{P}-w_{\pi}+s^{L \pi}\left(J_{v}-J_{\pi}\right)+s^{G}\left(J_{g}-J_{\pi}\right) \\
r W_{n 1} & =(\Phi-\mathcal{P}) x+\overline{y_{0}}+s^{G}\left(W_{n 0}-W_{n 1}\right)+\left(s^{L \pi}+s^{C \pi}\right)\left(W_{u}-W_{n 1}\right)
\end{aligned}
$$

and

$$
\begin{aligned}
r W_{n 0} & =\overline{y_{0}}+w_{g}+\lambda\left(W_{n 1}-W_{n 0}\right)+\left(s^{L \pi}+s^{C \pi}\right)\left(W_{u}-W_{n 0}\right) \\
\left(r+s^{C g}+s^{L g}\right) J_{g} & =-w_{g}+s^{L g} K+\lambda\left(J_{\pi}-J_{g}\right) .
\end{aligned}
$$

Note that we needed here $s^{L \pi}=s^{L g}$ otherwise two types of consumers. This leads to the firm's and 
consumer's consumption surpluses:

$$
\begin{aligned}
\left(r+s^{C \pi}+s^{L \pi}+s^{G}\right)\left(J_{\pi}-J_{g}\right) & =x \mathcal{P}-w_{\pi}+s^{L \pi} K-J_{g}\left(r+s^{C \pi}+s^{L \pi}\right) \\
& =x \mathcal{P}-w_{\pi}+s^{L \pi} K-\left(-w_{g}+s^{L g} K+\lambda\left(J_{\pi}-J_{g}\right)\right) \\
\left(r+s^{C \pi}+s^{L \pi}+s^{G}\right)\left(W_{n 1}-W_{n 0}\right) & =(\Phi-\mathcal{P}) x+\overline{y_{0}}+\left(s^{L \pi}+s^{C \pi}\right)\left(W_{u}-W_{n 0}\right)-r W_{n 0} \\
& =(\Phi-\mathcal{P}) x+\overline{y_{0}}+\left(s^{L \pi}+s^{C \pi}\right)\left(W_{u}-W_{n 0}\right)-\left(\overline{y_{0}}+\lambda\left(W_{n 1}-W_{n 0}\right)+\left(s^{L \pi}+s^{C \pi}\right)\left(W_{u}-\right.\right. \\
& =(\Phi-\mathcal{P}) x-\lambda\left(W_{n 1}-W_{n 0}\right)
\end{aligned}
$$

Bargaining over prices thus leads to, through $\left(W_{n 1}-W_{n 0}\right)\left(1-\alpha_{G}\right)=\left(J_{\pi}-J_{g}\right) \alpha_{G}$ :

$$
\alpha_{G}\left[x \mathcal{P}-w_{\pi}+s^{L \pi} K-\left(-w_{g}+s^{L g} K+\lambda\left(J_{\pi}-J_{g}\right)\right)\right]=\left(1-\alpha_{G}\right)\left[(\Phi-\mathcal{P}) x-\lambda\left(W_{n 1}-W_{n 0}\right)\right]
$$

and finally leads to:

$$
\mathcal{P} x=\left(1-\alpha_{G}\right) \Phi x+\alpha_{G}\left[w_{\pi}-w_{g}-s^{L \pi} K+s^{L g} K\right] .
$$

In the special case where wages are identical (see below), the price converges to a constant of parameters,

$$
\mathcal{P} x=\left(1-\alpha_{G}\right) \Phi x+\alpha_{G}\left(s^{L g}-s^{L \pi}\right) K
$$

which is even further simplified when labor turnover is the same in both stages $g$ and $\pi$.

$$
\mathcal{P} x=\left(1-\alpha_{G}\right) \Phi x .
$$

\section{E Wage determination in stage $g$ of CLG}

Assume that the wage remains constant between stages $g$ and $\pi$ and utility is linear. The labor surpluses of workers and bargaining firms are

$$
\begin{aligned}
\left(r+s^{L g}+s^{C g}\right)\left(W_{n 0}-W_{u}\right) & =\overline{y_{0}}+w_{g}+\lambda\left(W_{n 1}-W_{n 0}\right)-r W_{u} \\
\left(r+s^{C g}+s^{L g}\right)\left(J_{g}-J_{v}\right) & =0-w_{g}+\lambda\left(J_{\pi}-J_{g}\right)-\left(r+s^{C g}\right) K
\end{aligned}
$$

with

$$
r W_{u}=\overline{y_{0}}+f\left(W_{n 0}-W_{u}\right) .
$$

The capital gain of the worker when (s)he accesses consumption good $1 W_{n 1}-W_{n 0}$ is independent of $w_{g}$. The same is true from the capital gain of the firm $J_{\pi}-J_{g}$. The maximization of the Nash product in the labor market therefore leads to: $\left(1-\alpha_{L}\right)\left(W_{n 0}-W_{u}\right)=\alpha_{L}\left(J_{g}-J_{v}\right)$ leading to:

$$
\begin{aligned}
\left(1-\alpha_{L}\right)\left[\overline{y_{0}}+w_{g}+\lambda\left(W_{n 1}-W_{n 0}\right)-r W_{u}\right] & =\alpha_{L}\left[-w_{g}+\lambda\left(J_{\pi}-J_{g}\right)-\left(r+s^{C g}\right) K\right] \\
\Leftrightarrow w_{g} & =\alpha_{L}\left[0-\left(r+s^{C g}\right) K\right]+\left(1-\alpha_{L}\right)\left(r W_{u}-\overline{y_{0}}\right) \\
& +\lambda \alpha_{L}\left(J_{\pi}-J_{g}\right)-\left(1-\alpha_{L}\right) \lambda\left(W_{n 1}-W_{n 0}\right) .
\end{aligned}
$$

Interestingly the latter term can be simplified using the price bargaining equation, which holds in expectation and in equilibrium, delivering the wage equation:

$$
\begin{aligned}
w_{g} & =\left(1-\alpha_{L}\right)\left(r W_{u}-\overline{y_{0}}\right)+\alpha_{L}\left[-\left(r+s^{C g}\right) K\right] \\
& +\lambda\left(J_{\pi}-J_{g}\right) \frac{\alpha_{L}-\alpha_{G}}{1-\alpha_{G}}
\end{aligned}
$$

One can also replace the surplus of the firm by its forward value, using again

$$
\begin{aligned}
& J_{g}=\frac{Q_{g}}{1-Q_{\pi} Q_{g}}\left[\left(\frac{s^{L g} K-w_{g}}{\lambda}\right)+\left(\frac{x \mathcal{P}-w_{\pi}+s^{L \pi} K}{s^{G}}\right) Q_{\pi}\right] \\
& J_{\pi}=\frac{Q_{\pi}}{1-Q_{\pi} Q_{g}}\left[\left(\frac{x \mathcal{P}-w_{\pi}+s^{L \pi} K}{s^{G}}\right)+\left(\frac{s^{L g} K-w_{g}}{\lambda}\right) Q_{g}\right]
\end{aligned}
$$


one has:

$$
\begin{aligned}
J_{\pi}-J_{g} & =\frac{1}{1-Q_{\pi} Q_{g}}\left[Q_{\pi}\left(\frac{x \mathcal{P}-w_{\pi}+s^{L \pi} K}{s^{G}}\right)+\left(\frac{s^{L g} K-w_{g}}{\lambda}\right) Q_{g} Q_{\pi}-Q_{g} \frac{s^{L g} K-w_{g}}{\lambda}-\left(\frac{x \mathcal{P}-w_{\pi}+s^{L \pi} K}{s^{G}}\right) Q_{\pi} Q_{g}\right] \\
& =\frac{1}{1-Q_{\pi} Q_{g}}\left[\left[1-Q_{g}\right]\left(\frac{x \mathcal{P}-w_{\pi}+s^{L \pi} K}{s^{G}}\right)+\left(\frac{s^{L g} K-w_{g}}{\lambda}\right)\left[Q_{g} Q_{\pi}-Q_{g}\right]\right] \\
& =\frac{1}{1-Q_{\pi} Q_{g}}\left[\frac{x \mathcal{P}-w_{\pi}+s^{L \pi} K}{r+s^{L \pi}+s^{C \pi}+s^{G}} \frac{r+s^{L g}+s^{C g}}{r+s^{L g}+s^{C g}+\lambda}-\frac{s^{L g} K-w_{g}}{r+s^{L g}+s^{C g}+\lambda} \frac{r+s^{L \pi}+s^{C \pi}}{r+s^{L \pi}+s^{C \pi}+s^{G}}\right] .
\end{aligned}
$$

Note that

$$
\begin{aligned}
\frac{1}{1-Q_{\pi} Q_{g}} & =\frac{1}{1-\frac{\lambda}{r+s^{L g}+s^{C g}+\lambda} \frac{s^{G}}{r+s^{L \pi}+s^{C \pi}+s^{G}}} \\
& =\frac{\left(r+s^{L g}+s^{C g}+\lambda\right)\left(r+s^{L \pi}+s^{C \pi}+s^{G}\right)}{\left(r+s^{L g}+s^{C g}+\lambda\right)\left(r+s^{L \pi}+s^{C \pi}+s^{G}\right)-\lambda s^{G}} \\
& =\frac{\left(r+s^{L g}+s^{C g}+\lambda\right)\left(r+s^{L \pi}+s^{C \pi}+s^{G}\right)}{\left(r+s^{L g}+s^{C g}\right)\left(r+s^{L \pi}+s^{C \pi}\right)+\left(r+s^{L g}+s^{C g}\right) s^{G}+\left(r+s^{L \pi}+s^{C \pi}\right) \lambda}
\end{aligned}
$$

implying

$$
J_{\pi}-J_{g}=\frac{\left(x \mathcal{P}-w_{\pi}+s^{L \pi} K\right)\left(r+s^{L g}+s^{C g}\right)-\left(s^{L g} K-w_{g}\right)\left(r+s^{L \pi}+s^{C \pi}\right)}{\left(r+s^{L g}+s^{C g}\right)\left(r+s^{L \pi}+s^{C \pi}\right)+\left(r+s^{L g}+s^{C g}\right) s^{G}+\left(r+s^{L \pi}+s^{C \pi}\right) \lambda} .
$$

Simplifications arise when assuming identical turnover and credit shocks in each stage and finally with equal wages, one has

$$
\begin{aligned}
J_{\pi}-J_{g} & =\frac{\left(x \mathcal{P}-w_{\pi}+s^{L} K\right)-\left(s^{L} K-w_{g}\right)}{r+s^{L}+s^{C}+s^{G}+\lambda} \\
& =\frac{x \mathcal{P}-w_{\pi}+w_{g}}{r+s^{L}+s^{C}+s^{G}+\lambda} \\
& =\frac{x \mathcal{P}}{r+s^{L}+s^{C}+s^{G}+\lambda} .
\end{aligned}
$$

The wage equation thus becomes, using the notation $Q_{g}^{\prime}=\frac{\lambda}{r+s^{L}+s^{C}+s^{G}+\lambda}$ :

$$
\begin{aligned}
w_{g} & =\left(1-\alpha_{L}\right)\left(r W_{u}-\overline{y_{0}}\right)+\frac{\alpha_{L}-\alpha_{G}}{1-\alpha_{G}} Q_{g}^{\prime} x \mathcal{P}-\alpha_{L}\left(r+s^{C g}\right) K \\
& =\left(1-\alpha_{L}\right)\left(r W_{u}-\overline{y_{0}}\right)+\left(\alpha_{L}-\alpha_{G}\right) Q_{g}^{\prime} x \Phi-\alpha_{L}\left(r+s^{C g}\right) K .
\end{aligned}
$$

The price was replaced by its equilibrium expression in the last line. We also have the following simpler cases:

$$
\begin{aligned}
\text { CLG with } \alpha_{L}=\alpha_{G} \Rightarrow w_{g} & =\left(1-\alpha_{L}\right)\left(r W_{u}-\overline{y_{0}}\right)-\alpha_{L}\left(r+s^{C g}\right) K \\
\text { LG with } K=0 \Rightarrow w_{g} & =\left(1-\alpha_{L}\right)\left(r W_{u}-\overline{y_{0}}\right)+\left(\alpha_{L}-\alpha_{G}\right) Q_{g}^{\prime} x \Phi \\
\text { CL with } \lambda \rightarrow \infty, \alpha_{G}=0 \Rightarrow w_{g} & =\left(1-\alpha_{L}\right)\left(r W_{u}-\overline{y_{0}}\right)+\alpha_{L}\left[x \mathcal{P}-\left(r+s^{C g}\right) K\right] \\
\text { L with } K=0, \lambda \rightarrow \infty, \alpha_{G}=0 \Rightarrow w_{g} & =\left(1-\alpha_{L}\right)\left(r W_{u}-\overline{y_{0}}\right)+\alpha_{L} \mathcal{P} x .
\end{aligned}
$$

One can finally use the usual simplification of the value of unemployment to obtain the equations from the text.

$$
r W_{u}=z+\bar{y}^{0}+\frac{\alpha_{L}}{1-\alpha_{L}} f(\theta) J_{g}=z+\bar{y}^{0}+\frac{\alpha_{L}}{1-\alpha_{L}} \gamma \theta
$$




\section{F Alternative timing for wages and price determination}

Assume first that wages are different across states $g$ and $\pi$. The goods-market wage is still determined by:

$$
w_{g}=\operatorname{argmax}\left(\left(W_{g 0}-W_{u}\right)^{\alpha_{L}}\left(J_{g}-J_{v}\right)^{1-\alpha_{L}}\right) .
$$

In regards to wage $w_{\pi}$, three different timings can be explored (see Brzustowski (2015) for details).

- Timing 1 (wage $w_{\pi}$ negotiated before price): After $w_{g}$ is determined, and before having met a customer, the worker and the firm agree on a wage increase $w_{\pi}-w_{g}$ which will take effect as soon as the firm starts making profits. The new wage is the outcome of Nash-bargaining in anticipation of the later meeting of a customer.

- Timing 2 (price negotiated before wage $w_{\pi}$ ): Instead, this is only once his/her firm has started making profits by having met the customer that the worker renegotiates his/her wage and obtains a bonus $w_{\pi}-w_{g}$.

- Timing 3 (trilateral bargaining over $w_{\pi}$ and price): When a match is formed on the goods market, the customer, the firm's manager, and the worker of the firm gather and the three of them negotiate together over the price and the new wage.

In what follows, the outcomes of these three timings are presented independently after some preliminary results proved in Brzustowski (2015). Define the surplus of the consumer upon matching with a good:

$$
W_{\pi 1}-W_{\pi 0}=W_{g 1}-W_{g 0} \equiv \mathcal{S}_{M}^{W} .
$$

Notice that equation (72) also implies that the surplus gained by the worker of a newly profitable firm does not depend on his/her consumption situation:

$$
W_{\pi 1}-W_{g 1}=W_{\pi 0}-W_{g 0} \equiv \mathcal{S}_{\pi}^{W} .
$$

One has:

$$
\begin{aligned}
\mathcal{S}_{M}^{W} & =\frac{x(\Phi-\mathcal{P})}{r+s^{T}+\lambda} \\
\mathcal{S}_{\pi}^{W} & =\frac{w_{\pi}-w_{g}}{r+s^{T}+\lambda} .
\end{aligned}
$$

These expressions are to be compared with the firm's surplus upon matching on the goods market:

$$
J_{\pi}-J_{g}=\frac{x \mathcal{P}-\left(w_{\pi}-w_{g}\right)}{r+s^{T}+\lambda} .
$$

The goods market wage $w_{g}$ is independent of the future timing of negotiations. Indeed:

$$
\left(r+s^{C}+s^{L}+\theta q(\theta)\right)\left(W_{g 0}-W_{u}\right)=w_{g}-z+\lambda\left(\mathcal{S}_{M}^{W}+\mathcal{S}_{\pi}^{W}\right)=w_{g}-z+Q_{g}^{\prime}\left[x(\Phi-\mathcal{P})+\left(w_{\pi}-w_{g}\right)\right]
$$

and using that $J_{v}=K(\phi)$, one has:

$$
\left(r+s^{C}+s^{L}+\theta q(\theta)\right)\left(J_{g}-J_{v}\right)=-w_{g}+\gamma \theta-(1-\theta)\left(r+s^{C}\right) K(\phi)+Q_{g}^{\prime}\left[x \mathcal{P}-\left(w_{\pi}-w_{g}\right)\right] .
$$

As a result, independently of $\mathcal{P}$ and $w_{\pi}$, it is always the case that:

$$
\frac{\partial\left(J_{g}-J_{v}\right)}{\partial w_{g}}=-\frac{\partial\left(W_{g U}-W_{u}\right)}{\partial w_{g}} .
$$

It follows that the simple sharing rule in the main text will always hold:

$$
w_{g}=\left(1-\alpha_{L}\right) z+\alpha_{L}\left(\gamma \theta-(1-\theta)\left(r+s^{C}\right) K(\phi)\right)+Q_{g}^{\prime}\left[x \mathcal{P}-\left(w_{\pi}-w_{g}\right)-\left(1-\alpha_{L}\right) x \Phi\right] .
$$


Timing 1 In this case, the new wage $w_{\pi}$ is set before the price $\mathcal{P}$. We denote by $\alpha_{L}^{\pi}$ the bargaining weight of workers in that stage, to distinguish it from the above bargaining weight in stage $\mathrm{g} \alpha_{L}$. Reason by backward induction and derive first the price. Everything else having already been set, Nash-bargaining over the price leads to a simple sharing rule, with $\alpha_{G}$ the bargaining power of the consumer:

$$
\left(1-\alpha_{G}\right) \mathcal{S}_{M}^{W}=\alpha_{G}\left(J_{\pi}-J_{g}\right) .
$$

Using equations (74) and (76), this yields:

$$
\mathcal{P}=\left(1-\alpha_{G}\right) \Phi+\alpha_{G} \frac{w_{\pi}-w_{g}}{x} .
$$

Then the new wage $w_{\pi}$ can be derived. It is interpreted as an incentive to do a good job, which means that the worker's outside option in the negotiation is to do a "bad" job and let the firm remain in stage $g$. As a result, the new wage is set as:

$$
w_{\pi}=\operatorname{argmax}\left(\left(\mathcal{S}_{\pi}^{W}\right)^{\alpha_{L}^{\pi}}\left(J_{\pi}-J_{g}\right)^{1-\alpha_{L}^{\pi}}\right) .
$$

Taking into account the price rule (78), one has:

$$
\frac{\partial\left(J_{\pi}-J_{g}\right)}{\partial w_{\pi}}=-\left(1-\alpha_{G}\right) \frac{\partial \mathcal{S}_{\pi}^{W}}{\partial w_{\pi}} .
$$

Hence

Finally, one obtains:

$$
\alpha_{L}^{\pi}\left(J_{\pi}-J_{g}\right)=\left(1-\alpha_{L}^{\pi}\right)\left(1-\alpha_{G}\right) \mathcal{S}_{\pi}^{W}
$$

$$
\alpha_{L}^{\pi} \mathcal{P}=\left(1-\alpha_{G}\left(1-\alpha_{L}^{\pi}\right)\right) \frac{w_{\pi}-w_{g}}{x} .
$$

The system formed by equations (78) and (79) can be solved to:

$$
\begin{aligned}
\frac{w_{\pi}-w_{g}}{x} & =\alpha_{L}^{\pi} \Phi \\
\mathcal{P} & =\left(1-\alpha_{G}\left(1-\alpha_{L}^{\pi}\right)\right) \Phi .
\end{aligned}
$$

In this case, the goods-market wage $w_{g}$ has the following expression:

$$
w_{g}=\left(1-\alpha_{L}\right) z+\alpha_{L}\left(\gamma \theta-(1-\theta)\left(r+s^{C}\right) K(\phi)\right)+Q_{g}^{\prime}\left(\alpha_{L}-\alpha_{G}-\alpha_{L}^{\pi}\left(1-\alpha_{G}\right)\right) x \Phi .
$$

Timing 2 In this case, the new wage $w_{\pi}$ is set after the price $\mathcal{P}$. It is assumed for simplicity that the worker's outside option in this negotiation is to make the firm remain in stage $g$. This corresponds to the case of a strike: the worker refuses to serve the customer as long as (s)he has not gotten a wage increase. It could also be assumed that, rather than going on strike, the worker threatens to resign. However, this would lead to more complicated results. The derivation of the results under timing 2 follows a very similar structure to timing 1 and is left to the reader, who will obtain:

Bonus rule:

$$
\frac{w_{\pi}-w_{g}}{x}=\alpha_{L}^{\pi} \mathcal{P}
$$

Price rule:

$$
\left(1-\alpha_{L}^{\pi}\left(1-\alpha_{G}\right)\right) \mathcal{P}=\left(1-\alpha_{G}\right)\left(1-\alpha_{L}^{\pi}\right) \Phi+\alpha_{G} \frac{w_{\pi}-w_{g}}{x} .
$$

The system formed by equations (83) and (84) can be solved to:

$$
\begin{aligned}
\frac{w_{\pi}-w_{g}}{x} & =\left(1-\alpha_{G}\right) \alpha_{L}^{\pi} \Phi \\
\mathcal{P} & =\left(1-\alpha_{G}\right) \Phi .
\end{aligned}
$$

In this case, the goods-market wage $w_{g}$ has the following expression:

$$
w_{g}=\left(1-\alpha_{L}\right) z+\alpha_{L}\left(\gamma \theta-(1-\theta)\left(r+s^{C}\right) K(\phi)\right)+Q_{g}^{\prime}\left(\alpha_{L}-\alpha_{G}-\alpha_{L}^{\pi}\left(1-\alpha_{G}\right)\right) x \Phi .
$$

This is exactly the same expression as in timing 1 . 
Timing 3 In this case, $w_{\pi}$ and $\mathcal{P}$ are set simultaneously as the outcomes of a three-party Nash-bargaining:

$$
\left(w_{\pi}, \mathcal{P}\right)=\operatorname{argmax}\left[\left(\mathcal{S}_{M}^{W}\right)^{\alpha_{G}}\left(\mathcal{S}_{\pi}^{W}\right)^{\alpha_{L}^{\pi}}\left(J_{\pi}-J_{g}\right)^{1-\alpha_{G}-\alpha_{L}^{\pi}}\right] .
$$

The solution couple $\left(w_{\pi}, \mathcal{P}\right)$ will thus verify:

$$
\begin{aligned}
\left(1-\alpha_{G}-\alpha_{L}^{\pi}\right) \mathcal{S}_{M}^{W} & =\alpha_{G}\left(J_{\pi}-J_{g}\right) \\
\left(1-\alpha_{G}-\alpha_{L}^{\pi}\right) \mathcal{S}_{\pi}^{W} & =\alpha_{L}^{\pi}\left(J_{\pi}-J_{g}\right) .
\end{aligned}
$$

It follows that the bonus-rule/price-rule system takes the form:

$$
\begin{aligned}
\left(1-\alpha_{L}^{\pi}\right) \mathcal{P} & =\left(1-\alpha_{G}-\alpha_{L}^{\pi}\right) \Phi+\alpha_{G} \frac{w_{\pi}-w_{g}}{x} \\
\alpha_{L}^{\pi} \mathcal{P} & =\left(1-\alpha_{G}\right) \frac{w_{\pi}-w_{g}}{x} .
\end{aligned}
$$

This solves to:

$$
\begin{aligned}
\frac{w_{\pi}-w_{g}}{x} & =\alpha_{L}^{\pi} \Phi . \\
\mathcal{P} & =\left(1-\alpha_{G}\right) \Phi .
\end{aligned}
$$

In this case, the goods-market wage $w_{g}$ has the following expression ${ }^{5}$ :

$$
w_{g}=\left(1-\alpha_{L}\right) z+\alpha_{L}\left(\gamma \theta-(1-\theta)\left(r+s^{C}\right) K(\phi)\right)+Q_{g}^{\prime}\left(\alpha_{L}-\alpha_{G}-\alpha_{L}^{\pi}\right) x \Phi .
$$

\section{G Calibration Appendix: Source of data}

\section{G.1 Credit Market Parameters}

The discount rate $r$ is taken homogenous across countries at 0.0033 , which corresponds to an annual $4 \%$ rate (US T-bill). Eurostat's Business demography by size class [bd_9bd_sz_cl_r2] provides annual data on Employment share of enterprise deaths for Business economy except activities of holding companies. Dividing the data by 12, we obtain the model's credit separation rate $s^{C}$. Eurostat provides data for the period 2008-2011. Given the small variations over that period, $s^{C}$ is taken constant between 2005 and 2014, equal to the average of the data provided by Eurostat for each country. In the absence of information on the creditor's bargaining power $\alpha_{C}$, it is set to 0.5 .

Our main target on credit markets is the financial sector's share in GDP, denoted $\Sigma$. In the model, the GDP is $\bar{y}^{0}+x \mathcal{P} \mathcal{N}_{\pi}-\gamma \mathcal{V}-\kappa_{B} \mathcal{B}_{c}$, and therefore:

$$
\Sigma=\frac{\psi \mathcal{N}_{\pi}-w \mathcal{N}_{g}-\gamma \mathcal{V}-\kappa_{B} \mathcal{B}_{c}}{\bar{y}^{0}+x \mathcal{P} \mathcal{N}_{\pi}-\gamma \mathcal{V}-\kappa_{B} \mathcal{B}_{c}}
$$

Data are found in Eurostat's table National Accounts aggregates by industry [nama_10_a64], from which we take half of the value corresponding to financial activities. That is we have assumed that credit services to households and to businesses yield tantamount revenues.

Finally, in the absence of further evidence, we target an average six months to find credit for an entrepreneur in 2005. The credit matching factor $\chi_{C}$ is then fixed and this target is relaxed for the 2014 calibration. Similarly, it is assumed that the searching costs $\kappa_{B}$ and $\kappa_{I}$ are equal in $2005 ; \kappa_{I}$ being then fixed and $\kappa_{B}$ relaxed.

\footnotetext{
${ }^{5}$ Bear in mind that $\alpha_{G}$ and $\beta_{L}$ have been defined differently in this case.
} 


\section{G.2 Labor Market Parameters}

We target the unemployment rate $\mathcal{U}$ supplied by Eurostat [une_rt_m] for each country. We follow Shimer (2005)'s method and use Eurostat's Unemployment by duration of unemployment - quarterly data from the Labour Force Survey [lfsq_ugad], from which we obtain quarterly values for the short-term unemployment rate (i.e. the rate of unemployed persons who have been unemployed for less than one month), denoted $\mathcal{U}^{<1}$. Shimer (2005) uses it to estimate the job separation rate, $s^{C}+s^{L}$ in our model. Instead, we prefer to estimate a target for the job finding rate $f$, and to let $s^{L}$ be computed by the system. We consider then the rate of persons unemployed for more than one month $\mathcal{U}^{>1}=\mathcal{U}-\mathcal{U}^{<1}$. In the model:

$$
\mathcal{U}_{t}^{>1}=\left(1-f_{t-1}\right) \mathcal{U}_{t-1} .
$$

We have quarterly values for $\mathcal{U}^{>1}$ and monthly values for $\mathcal{U}$. Hence values for $f$ at the middle of each quarter can be computed. The annual averages give us a target for $f$ for each year. We target the job vacancy rate $\mathcal{V}$ given by Eurostat's Job vacancy statistics [jvs_q_nace2].

We target the share of wages in GDP $\mathcal{W}_{g d p}=\frac{(1-\mathcal{U}) w}{\bar{y}^{0}+x \mathcal{P N} \mathcal{N}_{\pi}-\gamma \mathcal{V}-\kappa_{B} \mathcal{B}_{c}}$ to correspond to the values found in Eurostat's GDP and main components (output, expenditure, and income) [namq_10_gdp], which gives quarterly data over 2005-2014 on the compensation of employees' share, taking into account wages and salaries as well as employers' social contributions. Data on unemployment benefit expenditures as a percentage of GDP are provided by Eurostat [spr_exp_gdp] from which we can estimate the ratio $z / w$ for 2005. Unemployment benefits $z$ are then fixed for the 2014 calibration. Finally, we target Silva and Toledo (2009)'s estimation that recruiting costs amount to $3.6 \%$ of a monthly wage. The vacancy posting cost $\gamma$ is then set constant for 2014 .

\section{G.3 Goods Market Parameters}

The marginal utility of consuming the frictional good $\Phi$ and the pure taste shock rate $\tau$ are taken as constant across countries and set as in Petrosky-Nadeau and Wasmer (2015). The quantity of numeraire in the economy $\bar{y}^{0}$ is set to $1 / 12$, such that individuals receive one unit of numéraire per year. The rate of capacity utilization is, in the steady state, equal to:

$$
\mu_{G}(\xi)=\frac{\lambda(\xi)}{s^{G}+s^{L g, \pi}+\lambda(\xi)}
$$

and the corresponding numbers are provided by Eurostat [ei_bsin_q_r2]. We target the share of the numeraire in total expenditures $\mathfrak{N}$ taken from Eurostat's Final consumption expenditure of households by consumption purpose (COICOP 3 digit) [nama_10_co3_p3]. The numeraire is assumed to correspond to the following categories (COICOP):

- Food and non-alcoholic beverages

- Alcoholic beverages, tobacco, and narcotics

- Water supply and miscellaneous services relating to the dwelling

- Electricity, gas, and other fuels

- Hospital services

- Operation of personal transport equipment

- Transport services

- Postal services

- Education

- Personal care

- Social protection 


\section{G.4 Supplementary tables}

\section{G.4.1 Benchmark case}

Table A.1 provides the equilibrium value of endogenous variables for each country-year.

\begin{tabular}{|c|c|c|c|c|c|c|}
\hline & Variable & & Year & UK & SPA & GER \\
\hline \multirow{8}{*}{ Credit } & \multirow{2}{*}{ available creditors } & \multirow{2}{*}{$\mathcal{B}_{c}$} & 2005 & .025 & .030 & .020 \\
\hline & & & 2014 & .025 & .025 & .034 \\
\hline & \multirow{2}{*}{ entrepreneurs in stage $c$} & \multirow{2}{*}{$\mathcal{N}_{c}$} & 2005 & .025 & .030 & .020 \\
\hline & & & 2014 & .024 & .024 & .012 \\
\hline & \multirow{2}{*}{ market tightness } & \multirow{2}{*}{$\phi$} & 2005 & 1.0 & 1.0 & 1.0 \\
\hline & & & 2014 & .94 & .98 & .34 \\
\hline & \multirow{2}{*}{ repayment } & \multirow[b]{2}{*}{$\psi$} & 2005 & .058 & .053 & .044 \\
\hline & & & 2014 & .051 & .065 & .037 \\
\hline \multirow{8}{*}{ Labor } & \multirow{2}{*}{ unemployment rate } & \multirow{2}{*}{$\mathcal{U}$} & 2005 & .048 & .092 & .110 \\
\hline & & & 2014 & .062 & .245 & .050 \\
\hline & \multirow{2}{*}{ vacancy rate } & \multirow{2}{*}{$\mathcal{V}$} & 2005 & .022 & .008 & .032 \\
\hline & & & 2014 & .023 & .006 & .029 \\
\hline & \multirow{2}{*}{ market tightness } & \multirow{2}{*}{$\theta$} & 2005 & .46 & .09 & .29 \\
\hline & & & 2014 & .37 & .02 & .58 \\
\hline & \multirow[b]{2}{*}{ wage } & \multirow[b]{2}{*}{$w$} & 2005 & .14 & .12 & .13 \\
\hline & & & 2014 & .14 & .13 & .13 \\
\hline \multirow{8}{*}{ Goods } & \multirow{2}{*}{ firms making profits } & \multirow{2}{*}{$\mathcal{N}_{\pi}$} & 2005 & .76 & .73 & .75 \\
\hline & & & 2014 & .77 & .57 & .80 \\
\hline & \multirow{2}{*}{ firms in stage $g$} & \multirow{2}{*}{$\mathcal{N}_{g}$} & 2005 & .20 & .18 & .14 \\
\hline & & & 2014 & .17 & .18 & .15 \\
\hline & \multirow{2}{*}{ price } & \multirow{2}{*}{$\mathcal{P}$} & 2005 & .21 & .19 & .18 \\
\hline & & & 2014 & .20 & .21 & .17 \\
\hline & \multirow{2}{*}{ gross domestic product } & \multirow{2}{*}{ GDP } & 2005 & .23 & .21 & .21 \\
\hline & & & 2014 & .22 & .20 & .21 \\
\hline
\end{tabular}

Table A.1: Endogenous variables.

\section{G.4.2 Robustness analysis}


Table A.2: Robustness of the decomposition in the limit case with only one type of friction UK Germany Spain

\begin{tabular}{llll|llll|lllll} 
Model: & C & L & G & Sum & C & L & G & Sum & C & L & G & Sum
\end{tabular}

\begin{tabular}{|c|c|c|c|c|c|c|c|c|c|c|c|c|c|}
\hline Benchmark & IVIOCI. & $50.8 \%$ & $14.5 \%$ & $48.0 \%$ & $113.3 \%$ & $40.9 \%$ & $18.0 \%$ & $51.7 \%$ & $110.7 \%$ & $80.3 \%$ & $5.3 \%$ & $36.3 \%$ & $\begin{array}{l}\text { sum } \\
121.9 \%\end{array}$ \\
\hline \multirow{2}{*}{ Finance's share in GDP } & $\Sigma^{*} 2$ & $45.1 \%$ & $15.5 \%$ & $52.7 \%$ & $113.3 \%$ & $33.6 \%$ & $19.8 \%$ & $57.0 \%$ & $110.4 \%$ & $77.9 \%$ & $5.9 \%$ & $38.1 \%$ & $121.9 \%$ \\
\hline & $\Sigma / 10$ & $55.7 \%$ & $13.5 \%$ & $44.2 \%$ & $113.4 \%$ & $46.5 \%$ & $16.6 \%$ & $47.7 \%$ & $110.9 \%$ & $82.6 \%$ & $4.7 \%$ & $34.5 \%$ & $121.8 \%$ \\
\hline \multirow{2}{*}{ Credit-search costs } & $\kappa_{B}=2 \kappa_{I}$ & $50.8 \%$ & $14.5 \%$ & $48.0 \%$ & $113.3 \%$ & $41.0 \%$ & $18.0 \%$ & $51.7 \%$ & $110.7 \%$ & $80.3 \%$ & $5.3 \%$ & $36.3 \%$ & $121.9 \%$ \\
\hline & $\kappa_{B}=\kappa_{I} / 2$ & $50.8 \%$ & $14.5 \%$ & $48.0 \%$ & $113.3 \%$ & $40.9 \%$ & $18.1 \%$ & $51.7 \%$ & $110.7 \%$ & $80.3 \%$ & $5.3 \%$ & $36.3 \%$ & $121.9 \%$ \\
\hline \multirow{2}{*}{ Credit finding rate } & $p * 2$ & $50.8 \%$ & $14.5 \%$ & $48.0 \%$ & $113.3 \%$ & $41.0 \%$ & $18.0 \%$ & $51.7 \%$ & $110.7 \%$ & $80.3 \%$ & $5.3 \%$ & $36.3 \%$ & $121.9 \%$ \\
\hline & $p / 2$ & $50.8 \%$ & $14.5 \%$ & $48.0 \%$ & $113.3 \%$ & $40.9 \%$ & $18.1 \%$ & $51.7 \%$ & $110.7 \%$ & $80.3 \%$ & $5.3 \%$ & $36.3 \%$ & $121.9 \%$ \\
\hline \multirow{2}{*}{$\begin{array}{l}\text { Creditor's bargaining } \\
\text { power }\end{array}$} & $\alpha_{C}=0.8$ & $50.5 \%$ & $14.5 \%$ & $48.3 \%$ & $113.3 \%$ & $40.2 \%$ & $17.9 \%$ & $52.6 \%$ & $110.7 \%$ & $80.7 \%$ & $5.1 \%$ & $36.0 \%$ & $121.8 \%$ \\
\hline & $\alpha_{C}=0.2$ & $49.6 \%$ & $14.7 \%$ & $49.0 \%$ & $113.3 \%$ & $40.6 \%$ & $18.5 \%$ & $51.7 \%$ & $110.7 \%$ & $78.7 \%$ & $5.8 \%$ & $37.4 \%$ & $121.9 \%$ \\
\hline \multirow{2}{*}{ Quantity of numeraire } & $\bar{y}^{0} * 2$ & $50.9 \%$ & $14.7 \%$ & $47.8 \%$ & $113.5 \%$ & $41.3 \%$ & $18.2 \%$ & $51.2 \%$ & $110.7 \%$ & $80.3 \%$ & $5.5 \%$ & $36.3 \%$ & $122.0 \%$ \\
\hline & $\bar{y}^{0} / 2$ & $49.9 \%$ & $14.6 \%$ & $48.8 \%$ & $113.3 \%$ & $35.1 \%$ & $19.2 \%$ & $56.0 \%$ & $110.4 \%$ & $80.2 \%$ & $5.3 \%$ & $36.4 \%$ & $121.8 \%$ \\
\hline Marginal utility & $\Phi=1.2$ & $50.8 \%$ & $14.5 \%$ & $48.0 \%$ & $113.3 \%$ & $41.0 \%$ & $18.0 \%$ & $51.7 \%$ & $110.7 \%$ & $80.3 \%$ & $5.3 \%$ & $36.3 \%$ & $121.9 \%$ \\
\hline of search good & $\Phi=1.1$ & $50.8 \%$ & $14.5 \%$ & $48.0 \%$ & $113.3 \%$ & $41.0 \%$ & $18.0 \%$ & $51.7 \%$ & $110.7 \%$ & $80.3 \%$ & $5.3 \%$ & $36.3 \%$ & $121.9 \%$ \\
\hline
\end{tabular}

